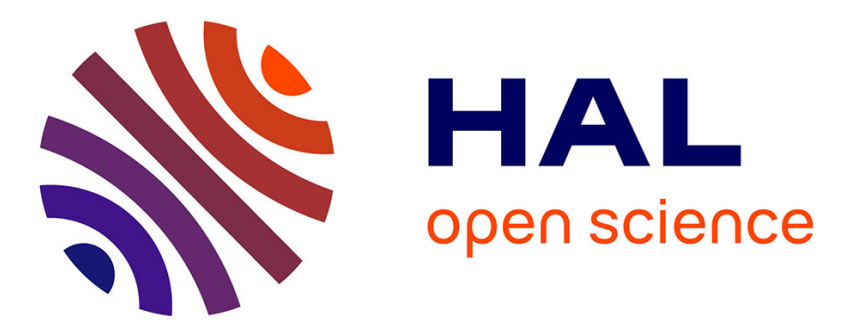

\title{
$\alpha$-Halogenoacetamides: versatile and efficient tools for the synthesis of complex aza-heterocycles
}

\author{
Abderrahman El Bouakher, Arnaud Martel, Sébastien Comesse
}

\section{To cite this version:}

Abderrahman El Bouakher, Arnaud Martel, Sébastien Comesse. $\alpha$-Halogenoacetamides: versatile and efficient tools for the synthesis of complex aza-heterocycles. Organic \& Biomolecular Chemistry, 2019, 17 (37), pp.8467-8485. 10.1039/C9OB01683J . hal-02313870

\section{HAL Id: hal-02313870 \\ https://hal-univ-lemans.archives-ouvertes.fr/hal-02313870}

Submitted on 11 Oct 2019

HAL is a multi-disciplinary open access archive for the deposit and dissemination of scientific research documents, whether they are published or not. The documents may come from teaching and research institutions in France or abroad, or from public or private research centers.
L'archive ouverte pluridisciplinaire HAL, est destinée au dépôt et à la diffusion de documents scientifiques de niveau recherche, publiés ou non, émanant des établissements d'enseignement et de recherche français ou étrangers, des laboratoires publics ou privés. 


\section{a-Halogenoacetamides: Versatile and Efficient Tools for the Synthesis of Complex aza-Heterocycles}

Received 00th January 20xx, Accepted 00th January 20xx

DOI: $10.1039 / x 0 x \times 00000 x$

\section{Introduction:}

$\alpha$-Halogenoacetamides are classical substrates that have long been employed by organic chemists. Even if, at first glance, they seem to be simple, they have proved over the years to be powerful intermediates for the synthesis of molecules of interest. The presence of the halogen atom in $\alpha$-position compared to the amide function allows a wide range of potential functionalizations at this position and thus prompted their use as versatile building blocks. Furthermore, the use of $\alpha$-halogenoacetamides as formal or real 1,3-dipole precursors led to the development of efficient domino ${ }^{1-6}$ or concerted strategies for the synthesis of various polysubstituted $\mathrm{N}$-heterocyclic molecules. Such approaches have recently attracted increasing interest since the development of aza-oxyallyl cation chemistry. The variety of structures reachable from these simple and tunable building blocks makes them good substrates for Diversity-Oriented Synthesis (DOS). ${ }^{7-10}$

The amide function is probably the main group in biologically relevant compounds, and therefore, many efforts have been devoted to their formation. ${ }^{11} \alpha$-Halogenoacetamides $\mathbf{A}(\mathrm{X}=\mathrm{Cl}, \mathrm{Br}, \mathrm{I})$ play an important role ${ }^{12}$ due to their ability to behave both as a nucleophile (at the nitrogen atom) and as an electrophile (at the carbon bearing the halogen) (Figure 1). One of the most interesting features of $\alpha$-halogenoacetamides is related to the high electrophilicity of the carbon bearing the halogen. Comparably to $\alpha$ halogenoketones or $\alpha$-halogenoesters, but to a slightly lower extent, $\alpha$-halogenoacetamides are among the most reactive halogenated electrophiles. This enhanced reactivity of a carbon

\footnotetext{
a. Normandie Univ, UNILEHAVRE, FR 3038 CNRS, URCOM, 76600 Le Havre, France. b. IMMM, UMR 6283 CNRS, Le Mans Université, 72085 Le Mans, France.

† Footnotes relating to the title and/or authors should appear here.

Electronic Supplementary Information (ESI) available: [details of any supplementary information available should be included here]. See DOI: $10.1039 / x 0 x x 00000 x$
}

atom bearing a halogen in alpha position of a carbonyl (higher than for benzyl or allyl groups) has been investigated in several studies and various explanations have been proposed. ${ }^{13}$ One of the most commonly admitted involves the contribution of the $\pi^{*}$ orbital of the carbonyl during the approach of the nucleophile. As the LUMO orbital is a combination of the $\sigma^{*} \mathrm{C}-\mathrm{X}$ with the $\pi^{*}$ orbital of the carbonyl, during the approach the nucleophile is also stabilized by overlap with the $\pi^{*}$ (Figure 2). ${ }^{13 d}$ The nucleophilic substitution is also considered to be stabilized by the pseudoenolate transition state that divides the negative charge of the nucleophile between the carbon and the oxygen.

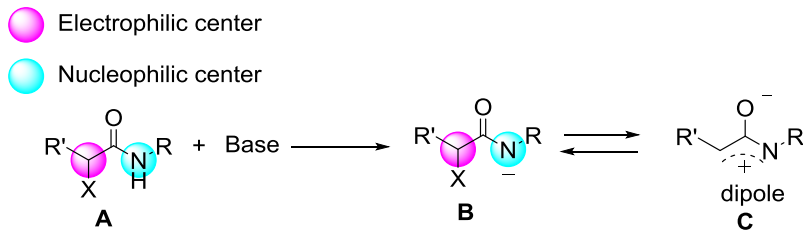

Figure 1.

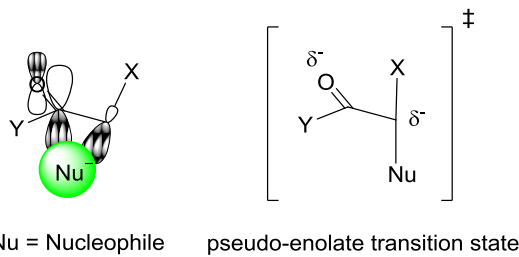

Figure 2.

In addition, contrary to the widely studied $\alpha$-haloesters and $\alpha$ haloketones, ${ }^{14} \alpha$-haloamides offer the opportunity to behave as a nucleophile in basic media by deprotonation of the amide $\mathrm{NH}$ to give amidate $\mathbf{B}$ and in some favorable conditions lead to the spontaneous formation of a dipole $\mathbf{C}$ (Figure 1 ).

This ability of $\alpha$-haloamides to behave as an electrophile, a nucleophile or both makes this type of compound particularly 
interesting in view of the variety of reactions that can be involved In this non-exhaustive review, only domino and cycloaddition reactions creating at least 2 bonds with the nitrogen atom and the carbon bearing the halogen resulting in a ring closure will be presented. Some applications of these strategies to the synthesis of backbones or molecules of biological interest will also be discussed (Figure 3).

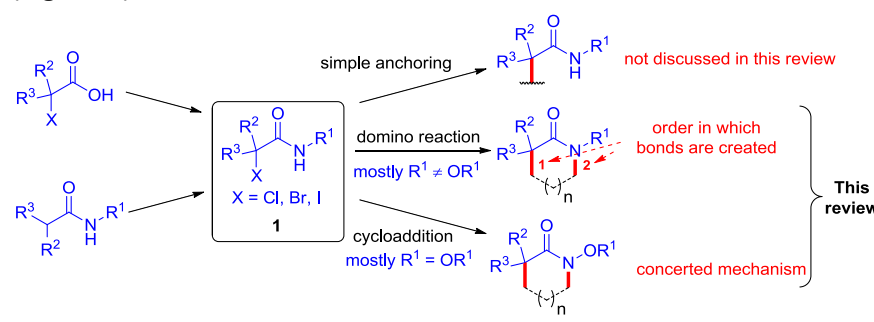

Figure 3. General access and different uses of $\alpha$-halogenoacetamides

The review will present the reactivity of $\alpha$-halogenoacetamides $\mathbf{1}$ in various types of reactions in the following order (in this paper all $\alpha$ halogenoacetamides will be numbered $\mathbf{1}$ ):

- Dimerization reactions

- Reaction with nucleophiles (Malonoate derivatives, ...) by addition to the $\alpha$-haloamide

- Reaction with electrophiles by first addition of the amidate

$\circ$ Addition to $\mathrm{C}=\mathrm{O}$
$\circ$ Addition to $\mathrm{C}=\mathrm{N}$
$\circ$ Addition to $\mathrm{C}=\mathrm{S}$
$\circ \quad$ Addition to $\mathrm{C}=\mathrm{C}$ and domino reactions and
related reactions.

- Coupling-Cyclization Sequence

The case of azaoxyallyl cations generated from an $\alpha$-halogenated Weinreb amide type was the object of a recent review ${ }^{15}$ but will be considered in the present paper. Indeed, it is interesting to have an overview of the dramatic change in the behavior of $\mathrm{N}$-alkyl vs $\mathrm{N}$ alkoxy $\alpha$-halogenoacetamides in order to better understand the particular reactivity of the latter such as the lower pKa of the Weinreb amide function compared to alkylamides. More precisely, these species can generate, in specific conditions, azaoxyallyl cations allowing the use of $[3+m]$-cycloaddition reactions for the synthesis of a wide variety of aza-heterocycles (Scheme 1).

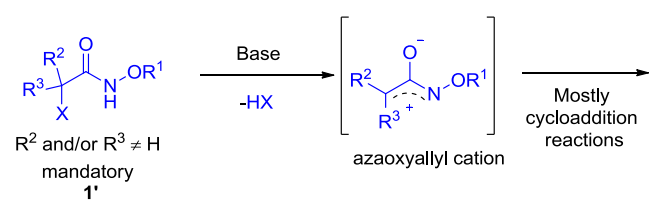

Scheme 1. Formation of the azaoxyallyl cation

$N$-alkyl $\mathbf{1}$ and $N$-alkoxy $\alpha$-halogenoacetamides $\mathbf{1}^{\prime}$ are easily accessible from commercially available 2-halogenoacetyl bromide or 2-halogenoacetic acid derivatives in reaction with a primary amine. Alternatively, they can also be obtained in a few stapes starting from substituted acetic acid derivatives (Scheme 2). ${ }^{13 e-h}$

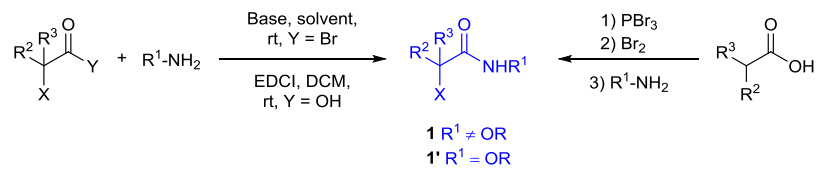

Scheme 2. Synthesis of $\boldsymbol{N}$-alkyl and $\boldsymbol{N}$-alkoxy $\alpha$-halogenoacetamides

\section{Dimerization of $\alpha$-halogenoacetamides 1 and their reaction with $\boldsymbol{\alpha}$-aminoesters}

2.1. Synthesis of Piperazine-2,5-diones through a domino dimerization/cyclization reaction:

Piperazine-2,5-dione scaffolds have been prevalent in the scientific literature due to their significant interest in biology and drug discovery. ${ }^{16-19}$ In recent years, the interest of these skeletons was highlighted in transition metal free reactions, used to promote carbon-carbon coupling between aryl and aryl halides by electron transfer processes. ${ }^{20-27}$

Dimerization reactions, if not desired, are the main side reaction of $\alpha$-halogenoacetamides. To limit these reactions, the reaction conditions have to be adjusted or highly reactive partners need to be involved. However, dimerization reactions were initially used successfully for the synthesis of piperazine-2,5-diones. The dimerization was first applied on simple $\alpha$-chloroacetamides 1 in the early 1980 s by Okawara et al. using phase transfer catalysis Duolite A-109 as catalyst in $50 \%$ of $\mathrm{NaOH} / \mathrm{CH}_{2} \mathrm{Cl}_{2}$ (Scheme 1). ${ }^{28}$ The synthesis of 1,4-disubstituted piperazine-2,5-diones 2 in a twophase medium $\left(\mathrm{CH}_{2} \mathrm{Cl}_{2}\right.$ /alkaline solution) in the presence of triethylbenzylammonium chloride (TEBA) as the phase transfer catalyst was reported by O'Reilly and co-workers (Scheme 3). ${ }^{29}$ Compounds $\mathbf{2}$ were also obtained in good yields by Cho and coworkers starting from $\alpha$-chloroacetamides 1 in acetonitrile in presence of $\mathrm{NaOH}$ as the base this time. ${ }^{30}$ It should also be mentioned that Hazra and co-workers ${ }^{31}$ reported piperazine-2,5dione derivatives $\mathbf{2}$ as antileishmanial agents and developed another alternative synthesis employing $\mathrm{NaH}$ in dry DMSO leading to the desired aza-heterocyclic systems in yields up to $95 \%$.

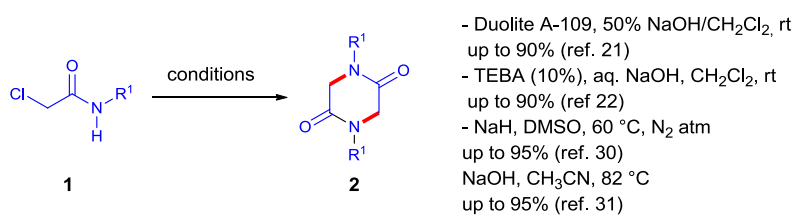

Scheme 1. Formation of Piperazine-2,5-diones 2 using phase transfer catalysis

The dimerization promoted by $\mathrm{NaH}$ in toluene was extended to 2bromopropanilides 1 on enantiopure and racemic mixtures leading to cis/trans ratios ranging from $8.5 / 1$ to $1 / 2$ due to partial racemization (Scheme 4). ${ }^{32}$ However, in a more polar solvent such as THF, the racemization is enhanced leading to cis/trans ratios ranging from $2 / 1$ to $4 / 1$. 


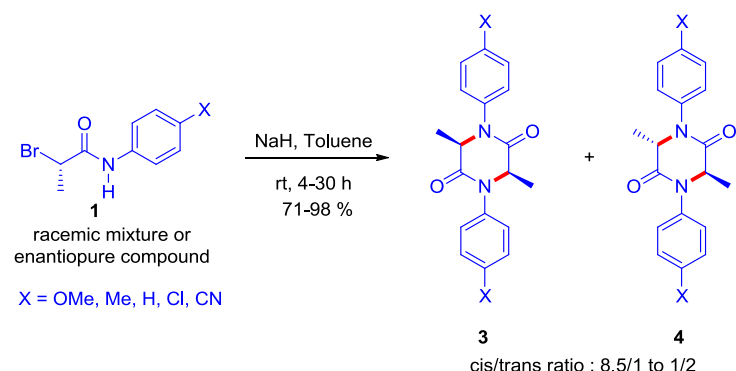

Scheme 4. Formation of piperazine-2,5-diones 3 and 4 from chiral $\alpha$ bromoacetamides 1

2.2. Synthesis of piperazine-2,6-diones via a domino $S_{N} 2 / C y c l i z a t i o n$ reaction with $\alpha$-aminoesters

Interestingly, it was also demonstrated that $\alpha$-bromoacetamides 1 were efficient precursors of piperazine-2,6-diones. In this particular case, they were reacted with $\alpha$-aminoesters 5 in basic conditions leading to piperazine-2,6-diones 6 in good yields (Scheme 5). ${ }^{33,34}$ The first step of the mechanism is the nucleophilic addition of the amino group of $\mathbf{5}$ onto the carbon bearing the bromine atom of $\mathbf{1}$ followed by the formation of the imide by addition of the amide function onto the methyl ester.

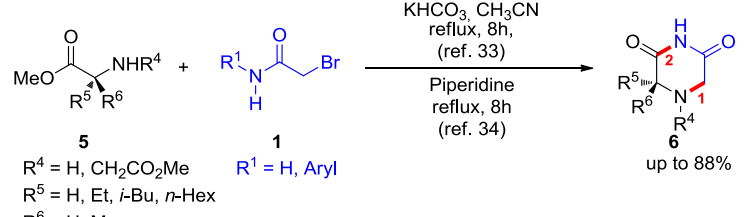

$$
\begin{aligned}
& \mathrm{R}^{6}=\mathrm{H}, \mathrm{Me}
\end{aligned}
$$

Scheme 5. Formation of piperazine-2,6-diones 6 by reaction with $\alpha$-aminoesters 5

\section{Reaction of $\alpha$-halogenoacetamide with nucleophiles}

3.1. Synthesis of $\beta-, \gamma$-lactams and bis- $\gamma$-lactams by reaction with malonate derivatives

The synthesis of lactams starting from $\alpha$-halogenoacetamides employing a domino process has been mostly described with $\alpha$ - or $\beta$-dicarbonyl compounds (such as malonate derivatives) as reaction partners. Among these strategies, the electrochemical reaction of diethyl bromomalonate $\mathbf{7}$ with $\alpha$-bromoacetamides $\mathbf{1}$ allowed the formation of various skeletons depending on the reaction conditions as demonstrated by the work of Moracci and co-workers (Scheme 6$)^{35}$ The electrogenerated diethyl malonate anion derivatives $\mathbf{A}$ and $\mathbf{B}$ were used to gain access to $\beta$-lactams $\mathbf{8}$ or spirobis- $\gamma$-lactam 9 depending on the substrates 1 employed. In the case of $N$-aryl $\alpha$-bromoacetamides 1 , the $\beta$-lactams 8 were obtained in yields ranging from 29 to $69 \%$ via the formation of carbanion $\mathbf{A}$. When the reaction was run starting from $N$-benzyl $\alpha$ bromoacetamide 1, the spirobis- $\gamma$-lactam 9 was isolated with $70 \%$ yield. In the same paper, the authors demonstrated that the products $\mathbf{1 1}\left(R^{1}=\mathrm{Bn}\right)$ and $\mathbf{9}$ could be obtained in $40 \%$ and $10 \%$ yield, respectively, by reaction between $N$-benzyl $\alpha$-bromoacetamide 1 and diethyl malonate $\mathbf{1 0}$ in the presence of $\mathrm{NaH}$ in DMF.

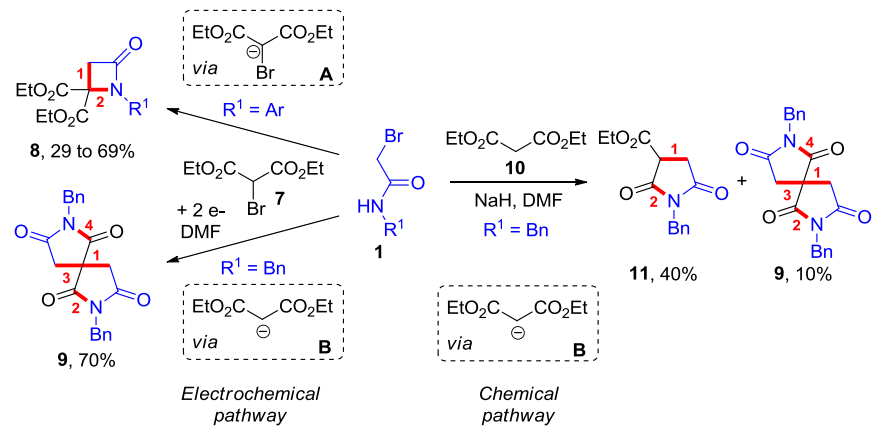

Scheme 6. Access to $\beta$-lactams $8, \gamma$-lactam 11 and spiro bis- $\gamma$-lactam 9

In order to explain both the formation of $\beta$-lactams $\mathbf{8}$ and spirobis- $\gamma$ lactam 9, two mechanisms were proposed (Scheme 7). Electrochemical reduction of diethyl bromomalonate 7 led to the formation of carbanion B which can further react with another equivalent of diethyl bromomalonate $\mathbf{7}$ to furnish the corresponding anion A. Addition onto $\mathrm{N}$-aryl $\alpha$-bromoacetamides 1 was followed by the nitrogen deprotonation and its addition onto the carbon bearing the bromine atom to furnish the $\beta$-lactams 8 . As for the spirobis- $\gamma$-lactam 9 , the authors stipulated the addition of anion $\mathbf{B}$ followed by the nitrogen addition onto one of the ester functions leading to the intermediate 11. Deprotonation of 11, followed by the addition of the corresponding anion onto another equivalent of $N$-benzyl $\alpha$-bromoacetamide 1 and a second nitrogen cyclization led to 9 . An independent synthesis of this spiroproduct 9, albeit in a lower $10 \%$ yield, was performed with diethyl malonate 10 in the presence of $\mathrm{NaH}$ in DMF to validate the passage via the anion $\mathbf{B}$.

$$
\text { Proposed mechanism for } 8
$$

Scheme 7. Electrochemical mechanisms for the synthesis of $\beta$-lactams 8 and spiro bis$\gamma$-lactam 9

In fact, the above strategy employing diethyl malonate proved to be an open route to spiro-compounds. Based on the above, Allous et al. published a modified and more comprehensive method for the synthesis of symmetrical $\left(R^{1}=R^{\prime 1}\right.$ in one step) and unsymmetrical $\left(R^{1} \neq R^{\prime 1}\right.$ in two domino steps) spiroimides 9 (Scheme 8). ${ }^{36}$ Due to the high biological interest of the spirooxindole ring system, the same domino strategy was successfully applied by Comesse, Daïch 
and co-workers for the formation of such spiro-junctions. ${ }^{37}$ In fact, the spirooxindole derivatives 15 were obtained from $N$-alkyl $\alpha$ bromoacetamides 1 following two pathways, one in two steps by reaction with dimethyl 2-(2-nitrophenyl)malonate $\mathbf{1 3}$ followed by a nitro-reduction/amino-ester cyclization and the second in one step by reaction with ethyl oxindole-carboxylate. Using a similar intermediate, Rammah et al. described the access to spirosuccinimide- $\gamma$-butyrolactone $\mathbf{1 2}$ via a sequence involving the saponification of the ester and the formation of the $\gamma$-butyrolactone by treatment with NBS or NIS to form the halogenated lactone displaying, in the case of the alkyne, an exocyclic double bond. ${ }^{38}$ More recently, gram scale access to succinimide derivative 11' (40 g batches) from $\alpha$-chloroacetamide 1 was performed by Bhogle and co-workers as a key step for the preparation of an aldose reductase inhibitor, namely AS-3201 (16). ${ }^{39}$

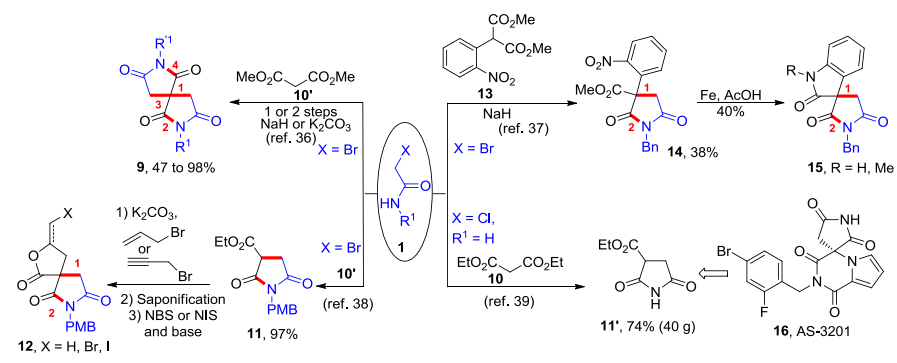

Scheme 8. Access to spiro-imides by reaction with malonate derivatives

It should be mentioned that other active methylene compounds 10 " can be used instead of dialkyl malonates in order to reach other $\mathrm{N}$-heterocyclic systems following the same domino pathway. ${ }^{40-42}$ When nitrile functions are present on the active methylenes 10", the formation of enamino $\gamma$-lactams 19, from the imine intermediate 18, can be observed. An interesting domino reaction on these lines was published by Tverdokhlebov and co-workers with the construction of 2 cycles during the process leading to 22 (Scheme 9). ${ }^{43}$
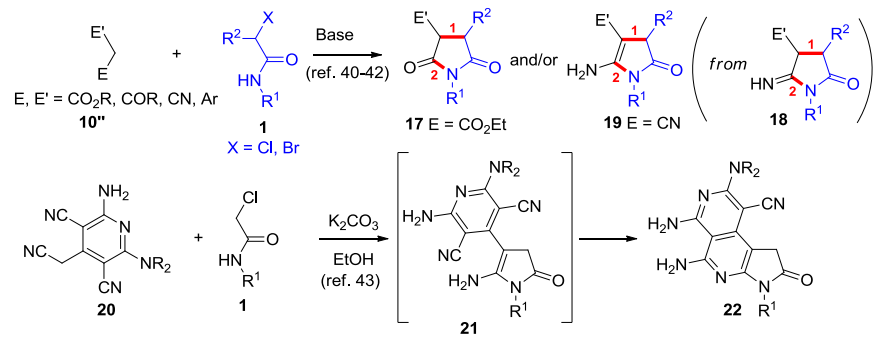

Scheme 9. Use of various active methylene compounds

3.2. Synthesis of spiro-imides derived from oxindole and isoindolinone derivatives

Allous et al. also demonstrated the efficiency of such strategies for access to spiroxindoles employing ethyl $\mathrm{N}$-methyloxindolecarboxylate 23 instead of malonate derivatives. ${ }^{37}$ In refluxing acetonitrile in the presence of $\mathrm{K}_{2} \mathrm{CO}_{3}$, the tricyclic products 24 were isolated in yields ranging from 58 to $84 \%$. Pesquet and Othman later employed the same strategy for the formation of spiroisoindolinones $\mathbf{2 6}$ engaging phthalimidines $\mathbf{2 5}$ (Scheme 10) as domino partner. ${ }^{44}$

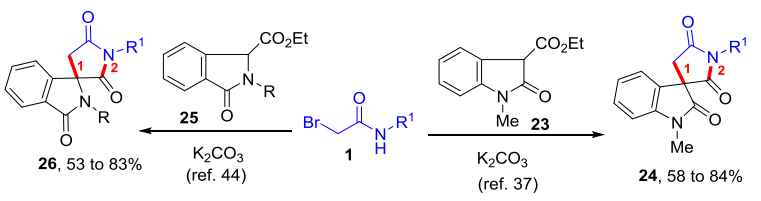

Scheme 10. Access to spirooxindole derivatives

3.3. Synthesis of erythrinan and homoerythrinan from $\alpha$-iodo acetamides

A beautiful use of $\alpha$-halogenoacetamides for the synthesis of erythrinan and homoerythrinan alkaloid cores was achieved by Tu and co-workers in 2006 (Scheme 11). ${ }^{45}$ One of the key steps in this strategy was the formation of the aza-heterocyclic 5-membered ring system with the wisely selected $N$-substituted $\alpha$ iodoacetamides $\mathbf{1}$. Refluxing ketone $\mathbf{2 7}$ in the presence of dimethyl carbonate and an excess of $\mathrm{NaH}$ led to the corresponding sodium enolate 28. Addition of $\mathrm{N}$-substituted $\alpha$-iodoacetamides $\mathbf{1}$ led to the formation of the bicyclic system $\mathbf{2 9}$ in a two-step domino sequence with yields ranging from 84 to $87 \%$ depending on the aromatic ring on acetamides 1. It is important to note that the same strategy for the synthesis of $\mathbf{3 1}(\mathrm{R}=\mathrm{Me})$ was developed at the same time by Padwa and co-workers. ${ }^{46}$
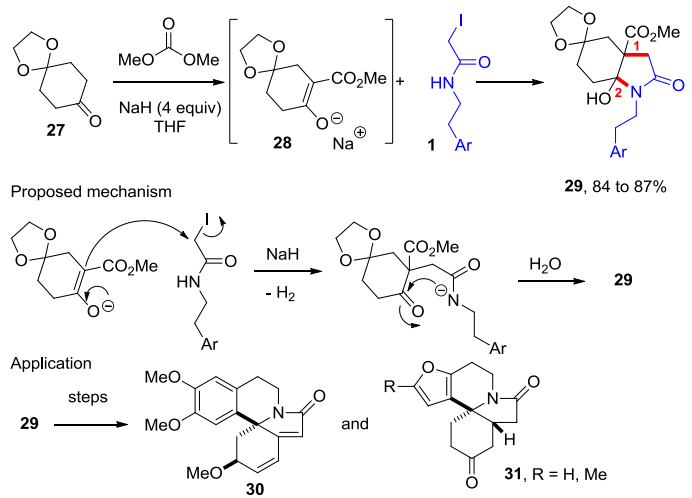

Scheme 11. Synthesis of the erythrinan and homoerythrinan cores

3.4. Synthesis of (-)-minovincine by addition of a silylated enol ether in the presence of fluoride salts

More recently, an attractive modified version of this transformation was reported by Nishida and co-workers for the enantioselective total synthesis of (-)-minovincine 34 (Scheme 12). ${ }^{47}$ In their case, the enol ether 32 resulting from a highly enantio- and totally diastereoselective Diels-Alder reaction was used instead of an enolate as described above. In the presence of TBAF, the desired $\gamma$ lactam $\mathbf{3 3}$ was obtained in $90 \%$ yield as a single diastereomer. The latter was converted in several steps into the desired indole 
alkaloid, a backbone well-known for its therapeutic properties, (-)minovicine 34.

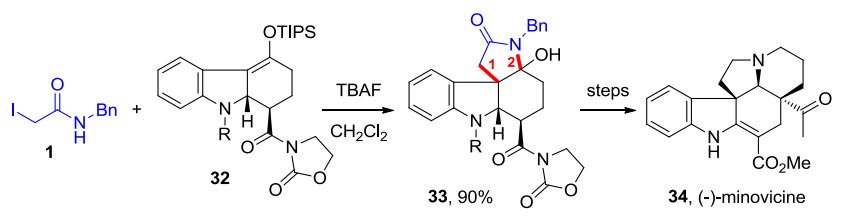

Scheme 12. $N$-Benzyl $\alpha$-iodoacetamide in the total synthesis of $(-)$-minovincine

\subsection{Synthesis of 2-imino-4-thiazolidin-4-ones by reaction with} potassium isothiocyanate

Interestingly, potassium thiocyanate ( $\mathrm{KSCN}$ ) reacts readily in the absence of any added base in acetonitrile and at room temperature with chloroacetamides 1 to furnish the corresponding 2-imino-4thiazolidin-4-ones 35 (Scheme 13). ${ }^{48-61}$ The good nucleophilicity of the sulfur atom and the high reactivity of the chloroacetamides 1 promote the initial nucleophilic substitution, followed by the addition of the amide function onto the $\mathrm{C} \equiv \mathrm{N}$ bond generating only $\mathrm{KCl}$ as side product

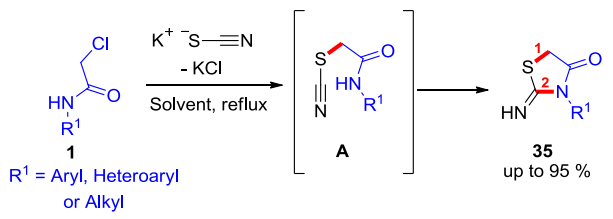

Scheme 13. Access to 2-imino-4-thiazolidin-4-ones from potassium isothiocyanate

3.6. Synthesis of oxazolidin-4-ones via a domino $O$-alkylation/azaMichael cyclization

An access to oxazolidin-4-ones $\mathbf{3 7}$ was reported by Marchetti when employing ambident potassium enolates 36 (Scheme 14). ${ }^{62}$ In the presence of a promoter, i.e. $\mathrm{Ag}^{+}$or $\mathrm{Ag}_{2} \mathrm{O}$, a domino $O$ alkylation/aza-Michael cyclization took place (see the proposed mechanism) and oxazolidin-4-ones $\mathbf{3 7}$ were isolated in yields ranging from 80 to $89 \%$.

$$
\mathrm{E}=\mathrm{come}, \mathrm{CO}_{2} \mathrm{Et}
$$

Scheme 14. Access to oxazolidin-4-ones via a domino $O$-alkylation/aza-Michae cyclization

3.7. Synthesis of oxazolidin-4-ones by addition to the $\mathrm{C}=\mathrm{O}$ bond of an amide, a ketone or an aldehyde
Interestingly, oxazolidin-4-ones can also be obtained by reaction with carbonyls. The first example of the addition of bromoacetamide 1 to a $\mathrm{C}=\mathrm{O}$ bond was described the beginning of the 80 s by D'Angeli and coll. onto DMF by treatment with sodium hydride or silver (I) oxide to form oxazolidinones 38 (Scheme 15). ${ }^{63-}$ ${ }^{65}$ The reaction is expected to proceed via the zwitterionic intermediate $\mathbf{A}$. The reaction was later extended by Maran et al. to dimethylacetamide and $\mathrm{N}$-methylpyrrolidinone by electrochemical activation, but gave modest yields. ${ }^{66}$

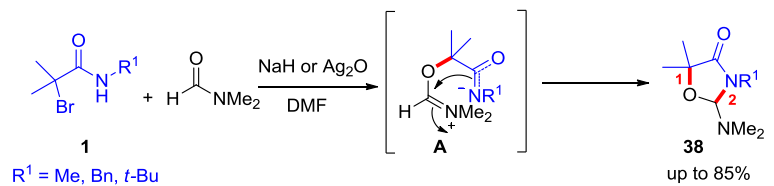

\section{Scheme15. Addition to DMF}

Shortly afterwards, the team of D'Angeli described the addition onto DMF. The addition of $\alpha$-bromoamides to the carbonyl of $\beta$ enaminones $\mathbf{3 9}$ or $\mathbf{4 2}$ was promoted by $\mathrm{NaH}$ to form, after hydrolysis of the resulting enamines $\mathbf{4 0}$ and $\mathbf{4 3}$, ketonyloxazolidin-4ones 41 and 44, respectively (Scheme 16). ${ }^{67}$

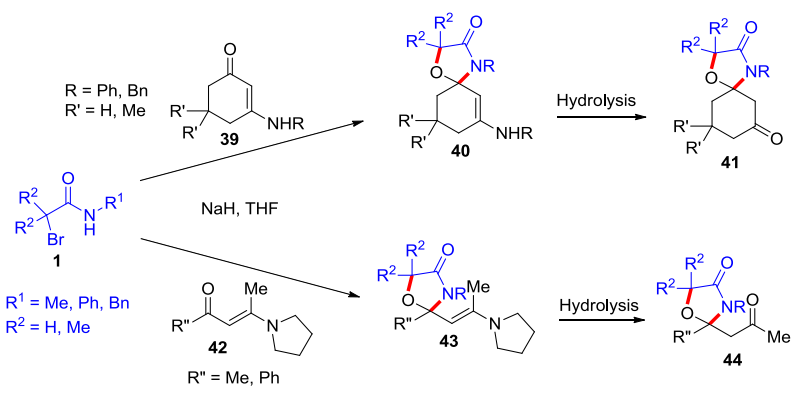

Scheme 16. Addition to enaminones

Oxazolidin-4-ones related to $\mathbf{4 6}$ were also obtained via a domino process involving a rearrangement and the subsequent migration of the carbonyl group as published by Martel, Comesse and coworkers. In the presence of water and using the uncommon $\mathrm{KNaCO}_{3}$ as base, the Michael acceptors $\mathbf{4 5}$ underwent hydrolysis. Then, the hydrolyzed Michael acceptors A reacted with $\alpha$-bromoacetamides 1 to give enol ethers $\mathbf{B}$ followed by an aza-Michael cyclization leading to the intermediates $C$. The latter were converted into $\mathbf{4 6}$ via an intramolecular retro-Claisen fragmentation. The domino process led exclusively and stereoselectively to the formation of oxazolidin-4ones 46 (Scheme 17). ${ }^{68}$ 


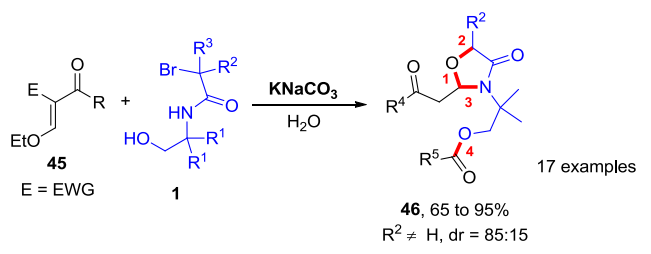

Proposed mechanism

Scheme 17. Alternative access to oxazolidin-4-ones to ketonyloxazolidin-4-ones

\section{Reaction of $\alpha$-halogenoacetamide with electrophiles}

4.1. Synthesis of oxazolidin-2,4-diones by addition to carbon dioxide or ammonium carbonate

Oxazolidin-2,4-diones $\mathbf{4 7}$ can be obtained from $\alpha$-chloroacetamides or $\alpha$-bromoacetamides $\mathbf{1}$ via the activation of carbon dioxide by an electrogenerated superoxide ion. The superoxide ion plays a key role in the deprotonation of the amide (Scheme 18). The amidate $\mathbf{A}$ formed then adds to $\mathrm{CO}_{2}$, then the carboxylate cyclizes to form the oxazolidin-2,4-diones 47 . $^{69,70}$

An alternative access to oxazolidin-2,4-diones $\mathbf{4 7}$ was published by Rossi and co-workers by treatment of $\alpha$-haloacetamides $\mathbf{1}$ with tetraethylammonium hydrogen (TEAHC) in acetonitrile (Scheme 18). ${ }^{71}$ The cyclic product 47 was obtained in average to good yields via the postulated intermediate $\mathbf{B}$. The authors proposed that the first step of the domino process was a condensation reaction followed by an intramolecular $\mathrm{S}_{\mathrm{N}} 2$ reaction with the formation of water and an ammonium salt as side products.

More recently, Saliu and co-workers (Scheme 18) ${ }^{72}$ described the synthesis of oxazolidin-2,4-diones 47 employing $\mathrm{CO}_{2}$ in an autoclave. The carboxylation of the amides 1 was promoted by DBU (1,8-diazabicyclo[5.4.0] undec-7-ene) via the carbamate salt 4 which undergoes an intramolecular $\mathrm{S}_{\mathrm{N}} 2$ cyclization leading to the desired oxazolidin-2,4-diones $\mathbf{4 7}$ in low to high yields.

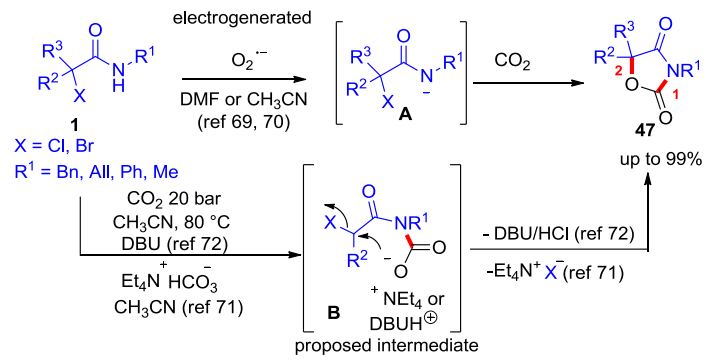

Scheme 18. Access to oxazolidin-2,4-diones via

4.2. Synthesis of imidazolidine-2,4-diones by addition onto isocyanates
Rmedi et al. described the addition $\alpha$-bromoacetamides 1 to isocyanates 48 to form hydrantoins 49 (Scheme 19). ${ }^{73}$. The high reactivity of isocyanates strongly favors the reaction with $\alpha$ bromoacetamides $\mathbf{1}$, leading to the formation of intermediate $\mathbf{A}$ which at $60{ }^{\circ} \mathrm{C}$ evolved spontaneously to form the products 49 in very good yields.

Interestingly, a dramatic change in the regioselectivity of the process was observed when replacing sulfonylisocyanates by arylisocyanates as presented in Scheme $19 .{ }^{74,75}$ In fact the latter afforded access to 2-imino-oxazolidin-4-diones 50, instead of hydrantoins 49, in good yields and mild conditions from $\alpha$ chloroacetamides 1 . These reactions were performed in $\mathrm{CH}_{3} \mathrm{CN}$ in the presence of $\mathrm{K}_{2} \mathrm{CO}_{3}$ as base.

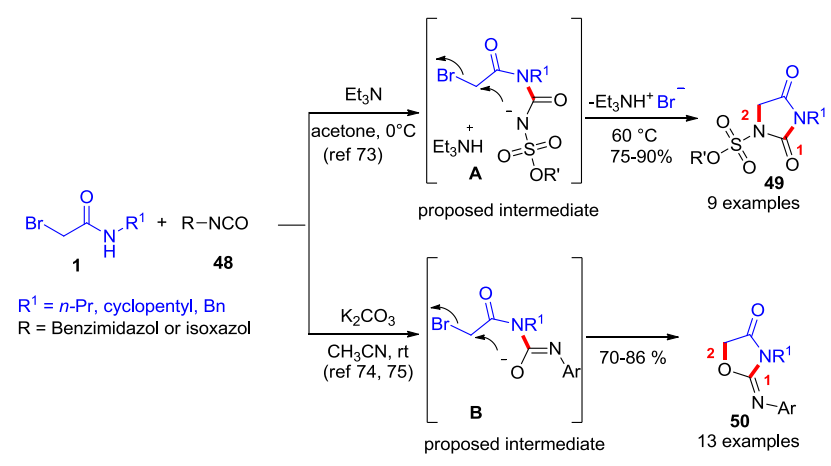

Scheme 19. Formation of Hydrantoins and 2-(imino)oxazolidin-4-ones

4.3. Synthesis of imidazolidin-4-ones by addition to an imine The annelation of a five-membered lactam ring fused to the (benzo)indole or carbazole nucleus was accomplished by the addition of $2 \alpha$-halogenoacetamides 1 onto imines 51 (Scheme 20)..$^{76-78}$

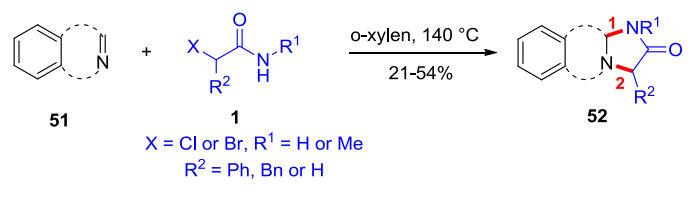

Scheme 20. Formation of imidazolidin-4-ones

An intramolecular addition of compound $\mathbf{5 5}$ onto an imine was published by Pearson and coll. (Scheme 21). ${ }^{79}$ In their paper, they described an elegant synthesis of the imidazolidin-4-one $\mathbf{5 6}$ via the imine B formed in situ from the aldehyde A. The iminium ion C, resulting from the quaternization of the imine, was trapped by the nitrogen atom of the amide function allowing the formation of the tetracyclic molecule $\mathbf{5 6}$ in a limited number of steps. 

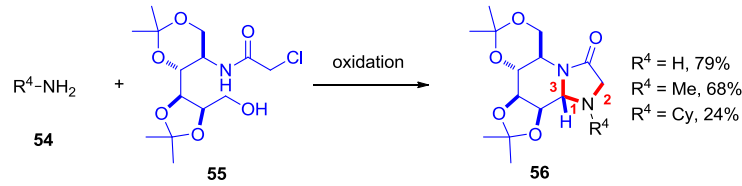

Plausible mechanism
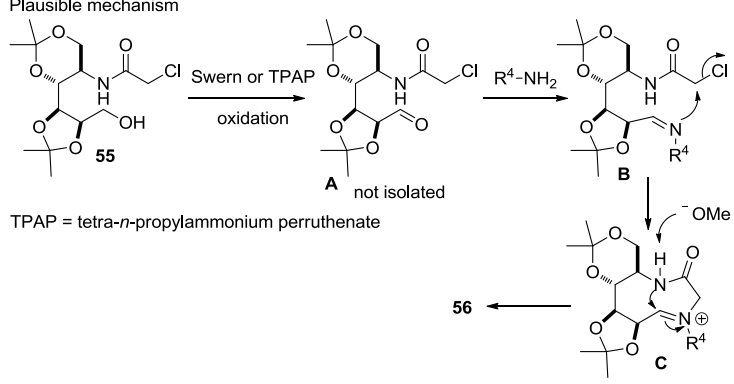

Scheme 21. Access to imidazolidin-4-ones

4.4. Synthesis of 2-imino-thiazolidin-4-ones by addition onto isothiocyanates

Similarly to potassium thiocyanate (Scheme 13), $\alpha$-haloacetamides 1 can react efficiently with isothiocyanates to form 2-imino-4thiazolidinones $\mathbf{5 3}$ but the sequence of the process is different. ${ }^{80-87}$ Contrary to potassium thiocyanate, in this case the reaction will first involve the addition of the amide onto the isothiocyanate, and then, the sulfur atom substitutes the halogen to form the thiazolidine-4-one 53. It should be noted that a soft base such as a carbonate is mandatory to promote this reaction with good yields (Scheme 22).

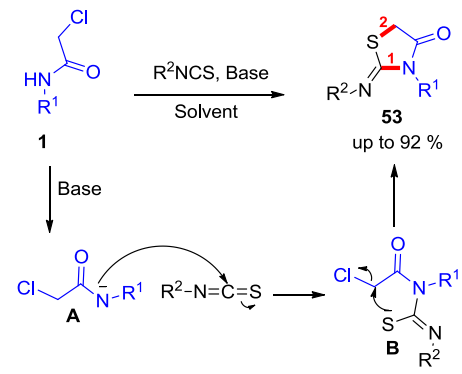

Scheme 22. Reactivity with isothiocyanates

4.5. Synthesis of spirothiazolidinones by addition onto thioamides

More surprisingly, $\alpha$-bromoamides $\mathbf{1}$ can also formally perform addition onto the $\mathrm{C}=\mathrm{S}$ bond of a thioamide as demonstrated with compound $\mathbf{5 7}$ (Scheme 23). ${ }^{88,89}$ This particular reactivity is related to the nucleophilicity of the sulfur atom of the thioamidate $A$ formed in the presence of the base $(\mathrm{NaH})$ and the lower pKa associated to the thioamidate. Indeed, the sulfur of the thioamidate can add to the $\alpha$-bromoamide 1 to form the intermediate $\mathbf{B}$ that cyclizes to form the spirothiazolidinone $\mathbf{5 8}$.

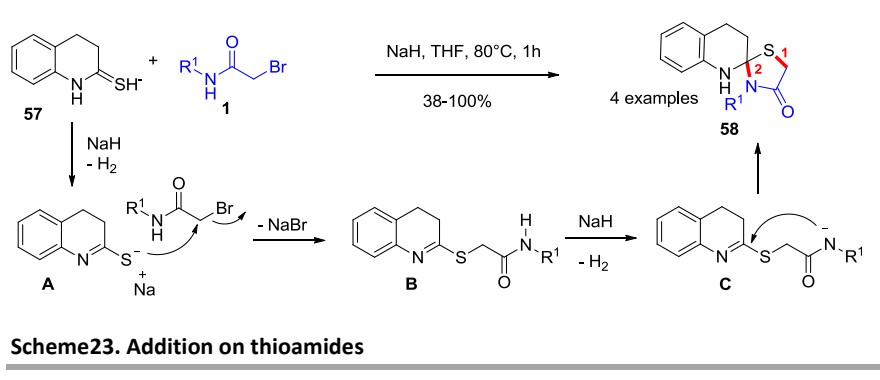

\subsection{Addition to a $\mathrm{C}=\mathrm{C}$ bond}

4.6.1. Formation of pyrrolidinones by a domino aza-Michael /nucleophilic substitution reaction

Comesse and co-workers developed a new domino sequence involving the $\alpha$-bromoacetamides 1 by reaction with various Michael acceptors 45 (Scheme 24). ${ }^{90}$ After the deprotonation of the nitrogen atom with $\mathrm{NaH}$, the domino sequence starts with an azaMichael addition leading to the anionic intermediate $\mathbf{A}$. This step is followed by a carbocyclization furnishing the desired $\gamma$-lactam 59 in yields ranging from 49 to $69 \%$ and excellent diastereoselectivity when $E \neq E^{\prime}$. This domino aza-Michael/nucleophilic substitution reaction was applied to the concise synthesis of the tricyclic core of (士)-martinelline $\mathbf{6 1}$ and was afterward successfully applied to the synthesis of the attractive tricyclic spirooxindole skeletons. ${ }^{91}$ When Michael acceptors $\mathbf{6 3}$ bearing an ethoxy group were engaged in the domino process, $\mathrm{N}$-acyliminium ion precursors $\mathbf{C}$ were isolated in high yields (Scheme $24, \mathrm{R}^{4}=\mathrm{OEt}$ )..$^{92}$ In order to prove the interest of such precursors, efficient inter- and intramolecular $\alpha$ amidoalkylation reactions were performed in the presence of a catalytic amount of $\mathrm{Tf}_{2} \mathrm{NH}(5 \mathrm{~mol} \%) .{ }^{93}$

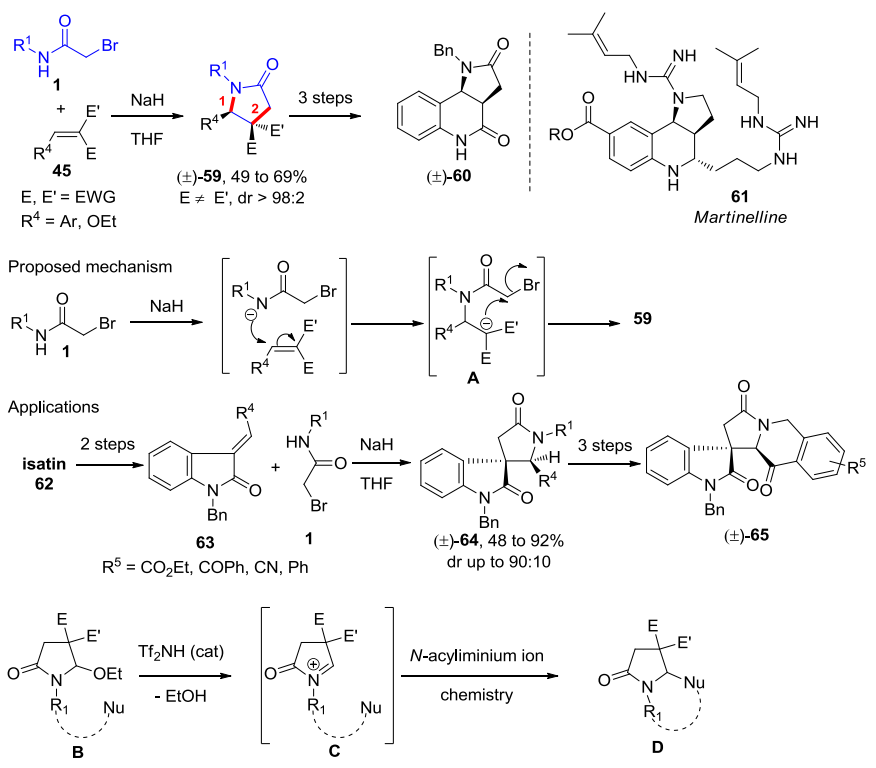

Scheme 24. Domino aza-Michael /nucleophilic substitution reaction

\subsubsection{Formation of polycyclic lactams}

The strategy was then extended to the synthesis of polysubstituted oxazolo-pyrrolidinones 66 (Scheme 25). ${ }^{94-96}$ For that purpose, 
hydroxyl $\alpha$-halogenoamides 1 and Michael acceptors $\mathbf{4 5}$ bearing a leaving group led efficiently, in the presence of $\mathrm{NaH}$ or $\mathrm{K}_{2} \mathrm{CO}_{3}$ as the base, to bicyclic lactams 66 . In this domino oxa-Michael/azaMichael/intramolecular nucleophilic substitution sequence assessed by DFT, three bonds were created and the main difference with the previous work was the formation of the intermediate enol ether A prior to the aza-Michael addition. It is worth noting that in most of the cases when two different electron-withdrawing groups were tested, only one diastereomer was detected by ${ }^{1} \mathrm{H}$ NMR on the crude mixture.
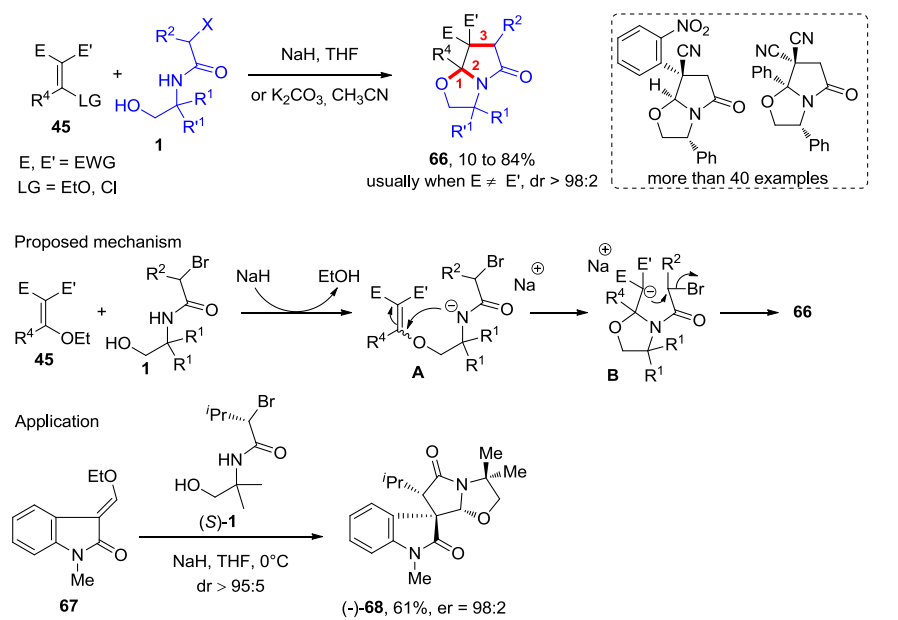

Scheme 25. Access to spiro-imides

More recently, Martel, Comesse and co-workers ${ }^{97}$ were able to synthesize 1,4-oxazepines 69 starting from the same substrates as above by shifting from a $\mathrm{C}-\mathrm{C}$ to a $\mathrm{C}-\mathrm{O}$ bond formation in the last step of the domino process (Schemes 25 and 26, compare the formation of bond number 3 ). This shift proved to be mostly directed by steric effects together with the use of $\mathrm{Cs}_{2} \mathrm{CO}_{3}$ as the base. As for the stereoselectivity, only one diastereomer was observed on the crude mixture (Scheme 26).

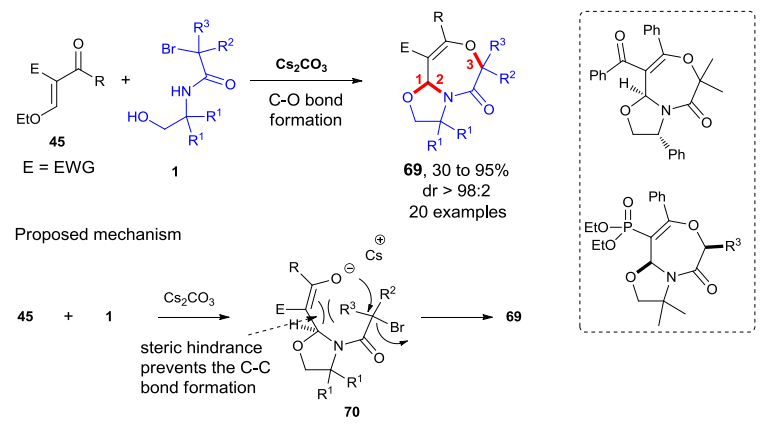

Scheme 26. Divergent access to $\gamma$-lactams and 1,4-oxazepines

One of the specific features of these $\alpha$-bromoamides is, as for $\alpha$ bromoesters or $\alpha$-bromoketones, related to their ability to transform the electrophilic center into a nucleophilic center by deprotonation of the carbon bearing the halogen in basic media. This reaction is further favored by the presence of a ketone in $\beta$ position as in the beautiful domino Darzens reaction/hemiaminal formation described by Kuramochi and co-workers in their development of the synthesis of natural products (Scheme 27). ${ }^{98-100}$ For that purpose, the authors engaged ketoaldehydes 71 with $\alpha$ bromo- $\beta$-ketoacetamides 1 in the presence of $\mathrm{Et}_{3} \mathrm{~N}$ and were rewarded with the creation of 3 bonds during the domino sequence. Indeed, the Darzens reaction was followed by an intramolecular addition of the nitrogen atom to lead directly to the desired bicyclic product 72. For some substrates they were unable to isolate the too unstable hemiaminal $\mathbf{A}$ or the Darzens reaction was not followed by the nitrogen cyclization. Finally, the domino Darzens reaction/hemiaminal formation led to the total synthesis of berkeleyamide $D(\mathbf{7 3})$ and rubrobramide (74).

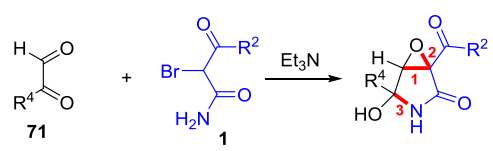

Proposed mechanism Application
steps

$72 \stackrel{\text { steps }}{\longrightarrow}$

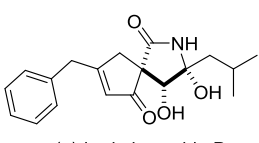

$( \pm)$-berkeleyamide $D$
73

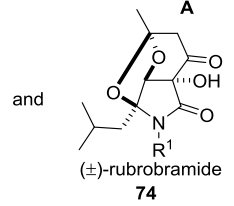

Scheme 27. $\alpha$-Bromo- $\beta$-ketoacetamides in domino Darzens reaction/hemiaminal formation.

Another example of a domino reaction including a Darzens reaction was proposed by $\mathrm{Yu}$ and co-workers for the diastereoselective synthesis of epoxide-fused benzoquinolizidine derivatives $\mathbf{7 6}$ (Scheme 28). ${ }^{101}$ In fact, when $\alpha$-chloro- $\beta$-ketoacetamides 75 possessing an internal Michael acceptor were treated with a base, i.e. $\mathrm{CsOH} . \mathrm{H}_{2} \mathrm{O}$, a domino aza-Michael addition/Darzens reaction took place leading to the formation of three bonds, three rings and three fully controlled stereogenic centers. It is important to point out that, in this case, the order in which the bonds are formed is reversed compared to the examples above, i.e. the $N-C$ bond was created prior to the $C-C$ bond since an intramolecular aza-Michael addition, assisted by the base, took place prior to the Darzens reaction leading to the tetracyclic system 76 .

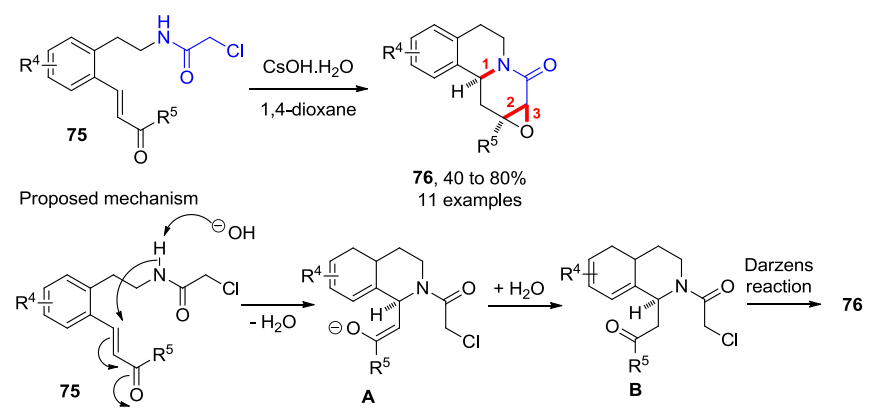

Scheme 28. $\alpha$-Chloro- $\beta$-ketoacetamides in domino aza-Michael/Darzens reaction.

\section{5. $\alpha$-Halogenoacetamide in a catalyzed domino coupling/cyclization sequence}




\subsection{Metal-catalyzed reactions}

The versatility of $\alpha$-haloamides as reagent presenting two different reactive sites is not limited to simple basic media, but can also be extended thanks to a coupling of the amide with an aromatic species, or a coupling involving the carbon bearing the halogen. The first example was reported by Bao and coll. ${ }^{102}$ with the copper catalyzed coupling of an 0 -iodophenol $\mathbf{7 7}$ and various chloro or bromo amides 1 . The nucleophilic substitution of the halogen by the phenate is described to occur first and to be followed by the intramolecular $\mathrm{Cu}(\mathrm{I})$-catalyzed coupling with the iodoaryl to give benzoxazin-3-ones 78 (Scheme 29). The second example was reported by Yin and coll. ${ }^{103}$ using palladium catalyzed intramolecular cyclization. The benzoxazin-3-ones 78 were also synthesized by Diz et al. ${ }^{104}$ using an efficient heterogeneous nanocatalyst Si-Cu for Ullmann intramolecular coupling reactions (Scheme 29).

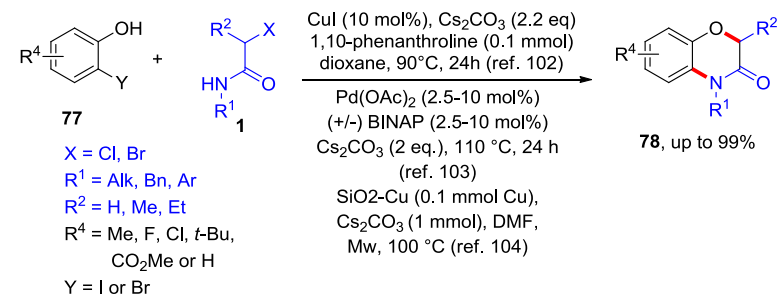

Scheme 29. Formation of benzoxazin-3-ones

Interestingly, another $\mathrm{Cu}(\mathrm{I})$-catalyzed reaction from $\alpha$ haloacetamides 1 mostly with acrylamides (EWG = amide function) or acrylic esters (EWG = ester function) $\mathbf{7 9}$ was developed by Nishikata and co-workers (Scheme 30). ${ }^{105}$ The authors managed to fully control the $\mathrm{N}$ - vs O-cyclization of the amide function of $\alpha$ haloacetamides 1 depending on the base, the source of copper (CuBr. Me $\mathrm{S}_{2} \mathrm{~S}$ vs $\mathrm{Cul}$ ), the ligand used and the presence of an ammonium salt, leading selectively to $\gamma$-lactams $\mathbf{8 0}$ or to the corresponding iminolactones $\mathbf{8 1}$. Remarkably, it proved possible to totally control the course of the domino process by tuning the reaction conditions and the desired heterocyclic systems $\mathbf{8 0}$ or $\mathbf{8 1}$ were isolated in good to high yields.

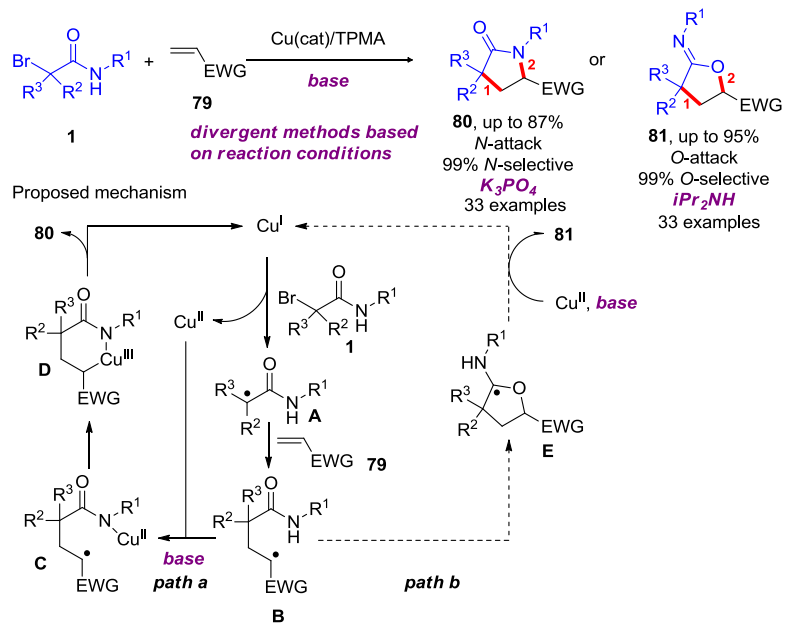

Scheme 30. Copper-catalyzed intermolecular aminolactonization

Among the $\alpha$-halooacetamides presented, the $\alpha, \alpha$-difluoro $\alpha$ haloacetamides display a very specific reactivity related to their ability to stabilize the radical formed by homolytic cleavage of the $\mathrm{C}-\mathrm{X}$ bond. Chen et al. ${ }^{106}$ published the synthesis of $\alpha, \alpha$-difluoro- $\gamma$ lactam derivatives $\mathbf{8 4}$ using a copper/amine catalyst via a tandem radical cyclization pathway from easily available alkenes 82 and $N$ aryl bromodifluoroacetamide 1 as starting materials. The reaction was initiated by a single electron transfer (SET) from the $\mathrm{Cu}(\mathrm{I})$ catalyst to compound $\mathbf{1}$ to produce radical $\mathbf{A}$. Then the addition reaction of $\mathbf{A}$ to alkene $\mathbf{8 2}$ gave an alkyl radical intermediate $\mathbf{B}$ (Scheme 31).

A similar reaction to prepare difluoro-p-lactams 84 or $\mathbf{8 5}$ was described by Lv et al. ${ }^{107,108}$ starting from monosubstituted alkenes $\mathbf{8 2}$ or mono or disubstituted alkynes $\mathbf{8 3}$, respectively (Scheme 31 ). The formation of the radical species $\mathbf{A}$ from $\alpha, \alpha$-difluoro $\alpha$ bromoacetamides 1 was promoted by $\mathrm{Cu}(\mathrm{I})$.

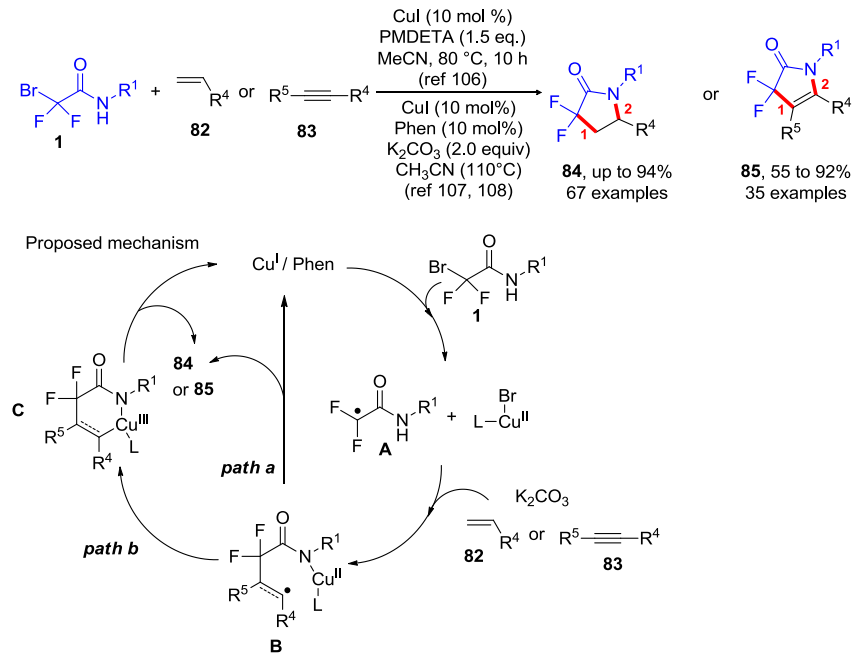

Scheme 31. Copper-catalyzed aminodifluoroalkylation of alkenes and alkynes: access to difluoro- $\gamma$-lactams

Iyer et al. $^{109}$ described the synthesis of $\gamma$-lactam derivatives 88 starting from 1,3-dienes 87 and $\alpha$-bromoacryl amides $\mathbf{8 6}$ (Scheme 32). This reaction is a modified Heck type reaction of $\alpha$-bromo acrylamides with 1,3-dienes catalyzed by $\mathrm{PdCl}_{2}\left(\mathrm{PPh}_{3}\right)_{2}$ (10 mol\%) using $\mathrm{ZnCl}_{2}$ as cocatalyst, in presence of $\mathrm{Na}_{2} \mathrm{CO}_{3}$ as base. The yields were mostly impacted by the substituents onto the diene and the nitrogen atom $\left(R^{1}=\right.$ Ar or Cy).

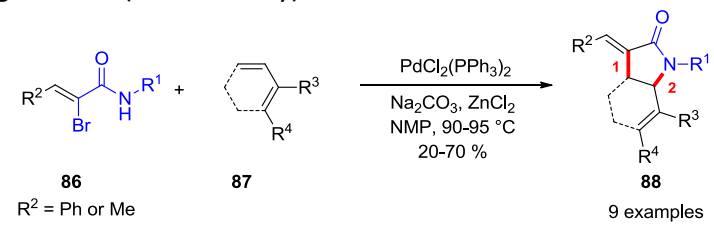

Scheme 32. Formation of $\boldsymbol{\gamma}$-lactams from $\alpha$-bromoacryl Pd-catalyzed amides

A straightforward access to optically active $\gamma$-lactams 91 bearing up to three fully controlled contiguous stereogenic centers, constructed from $\alpha$-halogenoamides 1 and chloroalkenes 89, was 
developed by Kanbayashi et al. (Scheme 33). ${ }^{110}$ Their strategy was based on an asymmetric auto-tandem allylic amidation/atomtransfer radical cyclization (ATRC) reaction, which proceeds in a highly regio-, diastereo-, and enantioselective manner, catalyzed solely by a planar-chiral $\mathrm{Cp}^{\prime} \mathrm{Ru}$ complex. The first step in this domino process was the enantioselective allylic amidation of $\alpha$ haloacetamides 1 followed by a diastereoselective ATRC, both catalyzed by the same catalyst.

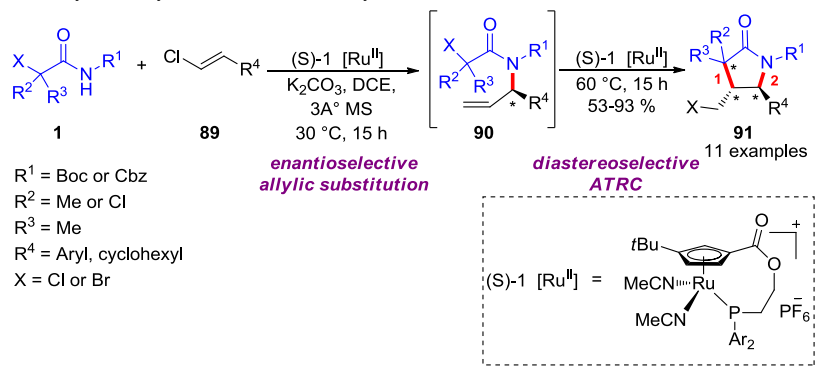

Scheme 33. Formation of $\boldsymbol{\gamma}$-lactams catalyzed by planar-chiral $\mathbf{C} p^{\prime} \mathbf{R u}$ complex

\subsection{Transition-Metal-free reaction}

The synthesis of difluoro- $\gamma$-lactams 84 from $\alpha, \alpha$-difluoro $\alpha$ iodoacetamides 1 was reported by Chen and co-workers in 2012 via a radical addition onto alkenes 82 (Scheme 34$).{ }^{111}$ In the presence of sodium hydrosulfite, radical species A were generated. Regioselective addition onto alkenes $\mathbf{8 2}$ and subsequent trapping of the resulting radical with iodine led to $\gamma$-iodo amide C. $\mathrm{S}_{\mathrm{N}} 2$ cyclization of the nitrogen atom and deprotonation of the intermediate ammonium salt formed led to the desired $\gamma$-lactam 84 .

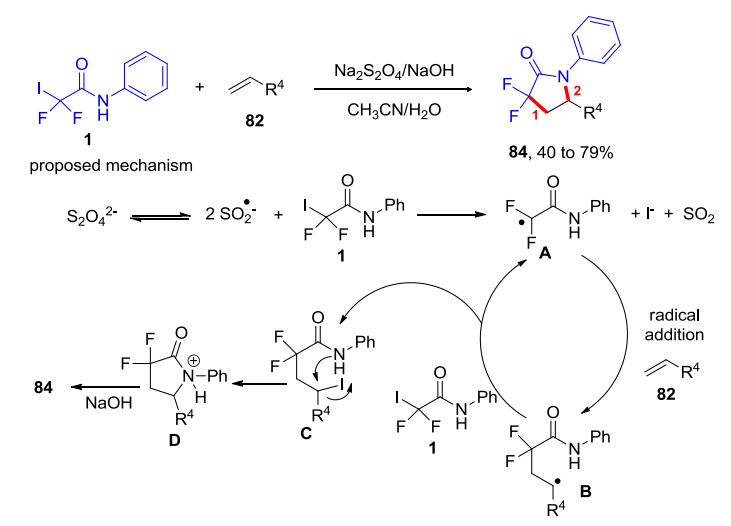

Scheme 34. Access to difluoro- $\gamma$-lactams via a radical addition onto alkenes

\subsection{Photoredox/iodide-catalyzed reaction}

Zhu and co-workers lately demonstrated that the $\alpha, \alpha$-difluoro $\alpha$ bromoacetamides $\mathbf{1}$ are also powerful tools for a cascade photoredox/iodide catalysis in order to access difluoro- $\gamma$-lactams 93 in good yields (Scheme 35). ${ }^{112}$ In order to prevent the formation of side products from possible competitive reaction pathways when employing radical chemistry, the authors applied a mild and dual catalytic protocol allowing the synthesis of various difluoro- $y$ lactams 93 in good to excellent yields. The proposed mechanism involved two catalytic cycles, the first one leading to the radical intermediate $\mathbf{A}$ via a single-electron-transfer (SET) radical process thanks to a photocatalyst, $f a c-\operatorname{Ir}(\mathrm{ppy})_{3}$. After addition onto alkene 92 and another oxidative step, the carbocation $\mathbf{C}$ was quickly trapped by iodide ion preventing side reactions. $\gamma$-lodoacetamides D then underwent an intramolecular $\mathrm{S}_{\mathrm{N}} 2$ reaction leading to difluoro-p-lactams 93 while regenerating the iodide ion.

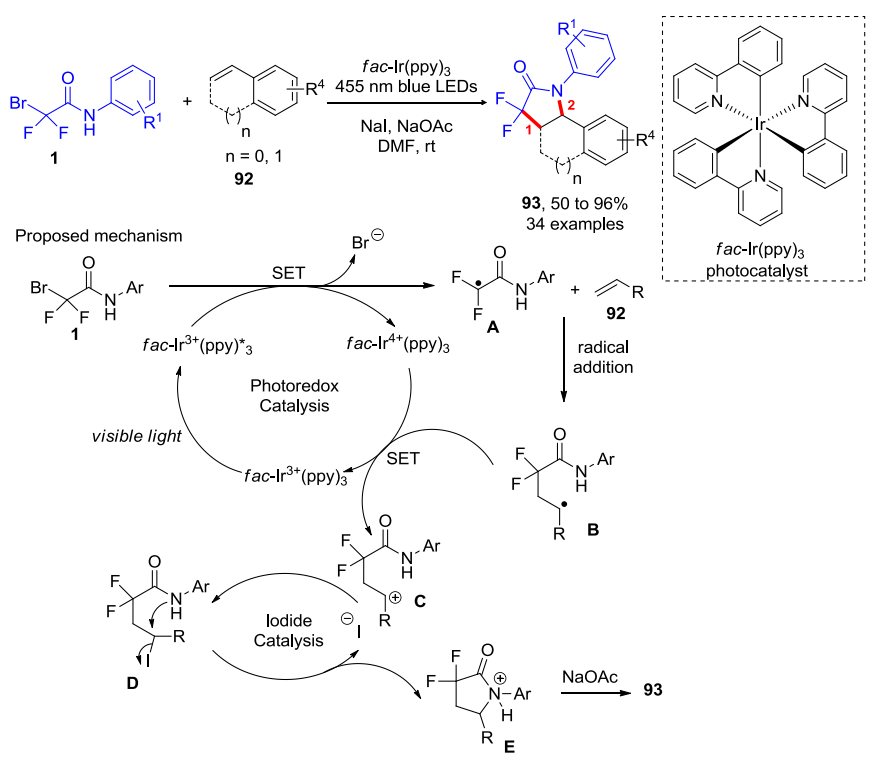

Scheme 35. Access to difluoro- $\gamma$-lactams via a cascade photoredox/iodide catalysis

5.4. Metal-catalyzed intramolecular cyclization: access to polycyclic $\gamma$-lactams

A Pd-catalyzed intramolecular aminoalkylation starting from $\alpha$-halo acetamides $\mathbf{9 4}$ bearing an alkene moiety was published recently by Yang and co-workers (Scheme 36). ${ }^{113}$ This intramolecular Pdcatalyzed coupling is highly complementary to the previously presented $\mathrm{Cu}(\mathrm{I})$-catalyzed aminoalkylations (see Schemes 30 and 31) and opens the access to a large variety of polycyclic lactams 95 in a limited number of steps. The two bonds were created by an aminopalladation followed by a reductive elimination regenerating the catalyst. Note that this palladium catalysis did not require the use of an expensive and/or sensitive ligand or external oxidant.

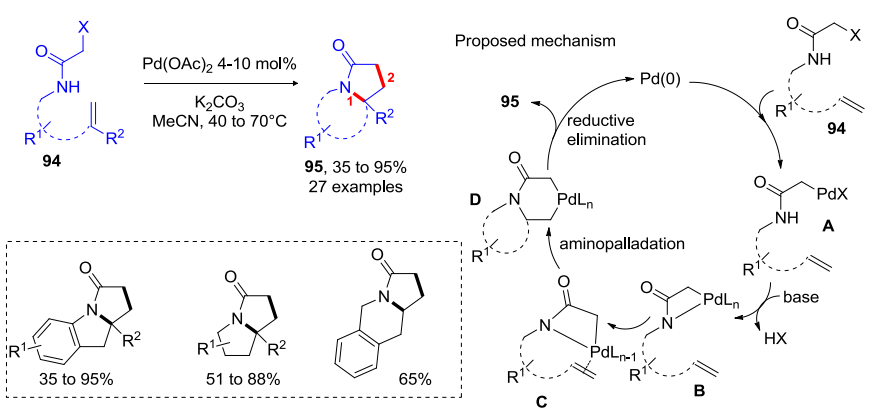

Scheme 36. Palladium-catalyzed intramolecular aminoalkylation: access to polycyclic lactams

6. Use of $N$-alkoxy $\alpha$-halogenoacetamides 
As stipulated in the introduction section of this review, there is a dramatic change in the reactivity of $\alpha$-halogenoacetamides when shifting from $\mathrm{N}$-alkyl to $\mathrm{N}$-alkoxy derivatives. While the former can be powerful domino partners as highlighted in the previous section, the latter have mainly been used as aza-oxyallyl cation precursors. These cations were first reported by Kikugawa and co-workers in the presence of a base in mild conditions thanks to the lower pKa of $\mathrm{N}$-alkoxy compared to $\mathrm{N}$-alkyl amides. The chemistry of azaoxyallyls has been lately a topic of growing interest due to their high ability to promote $[3+\mathrm{m}]$ cycloaddition reactions with various types of partners (dipole, $\mathrm{C}=\mathrm{C}, \mathrm{C}=\mathrm{O}$, diene, ...) and is the subject of a recent review. ${ }^{15}$ The present review will summarize the main results and discuss the most recent' ones published since, and will focus on the differences in reactivity between $N$-alkyl and $N$-alkoxy $\alpha$ halogenoacetamides.

\subsection{First, aza-oxyallyl cations in [3+4]-cycloadditions}

Based on the previously reported generation of aza-oxyallyl cations by Kikugawa, Jeffrey's group was able in $2011^{114}$ to develop the first aza-[3+4] cycloaddition with cyclic dienes. After screening various solvents, bases and Lewis acid additives, the best reaction conditions were found to be, depending on the $N$-alkoxy $\alpha$ halogenoacetamides employed, either trifluoroethanol (TFE) or hexafluoroisopropanol (HFIP) with triethylamine as a base. Then, various alkoxyamides were reacted with furan $(96, Y=0)$ or cyclopentadiene $\left(\mathbf{9 7}, \mathrm{Y}=\mathrm{CH}_{2}\right.$ ) via the aza-oxyallyl cations $\mathbf{A}$, and cycloadducts 98 were isolated in yields ranging from 52 to $86 \%$. This result involving furan as cycloreactant is remarkable considering the poor reactivity of furans in cycloaddition reactions. It should be mentioned that no reaction occurred when $N$-benzyl $\alpha$ halogenoacetamide 1 was employed and this result was assessed by computational studies comparing the influence of the substituent onto the nitrogen atom. No evidence of the formation of an azaoxyallyl cation could be found when the OBn was replaced by a simple $\mathrm{Bn}$ on the amide. Finally, it was also shown that, as expected for the formation of cationic species, no reaction occurred when starting from primary $N$-alkoxy bromoamide $1^{\prime}\left(R^{2}=R^{3}=H\right.$, Scheme 37).

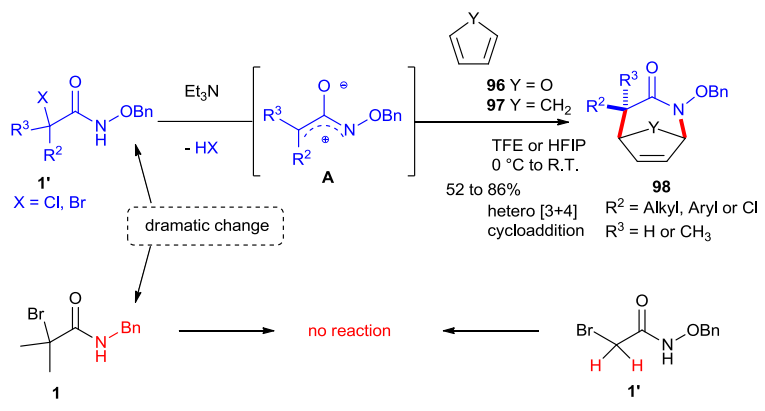

Scheme 37. First example of the generation together with some reactivity of azaoxyallyl cationic intermediates $\mathrm{A}$

Shortly afterwards, Jeffrey et al. described an intramolecular version of this cycloaddition reaction. ${ }^{115-117}$ Since these first papers demonstrating the high potential of $\mathrm{N}$-alkoxy bromoamides as aza- oxyallyl cation precursors, many applications involving them have been reported.

Recently, Zhao et al. ${ }^{118}$ have revisited this chemistry for the development of a rapid access to multisubstituted benzodiazepine derivatives $\mathbf{1 0 0}$ using a formal $[3+4]$ cycloaddition reaction between azaoxyallyl cations and anthranils 99 (Scheme 38 ). These attractive polycyclic systems were obtained under mild conditions usually in high yields via the proposed formation of the zwitterionic intermediate $\mathbf{A}$.

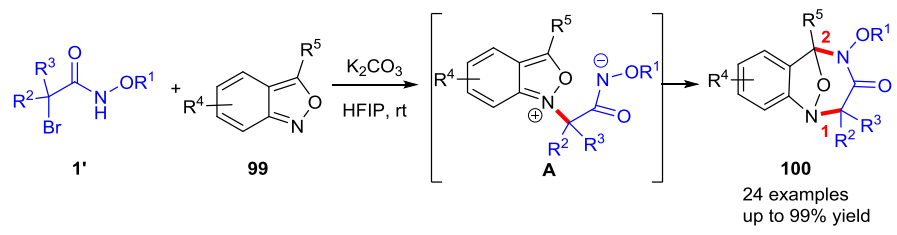

Scheme 38. $[3+4]$-cycloadducts from anthranil derivatives

\subsection{Aza-oxyallyl cations in $[3+3]-$ cycloadditions and recent developments}

These aza-oxyallyl cations also proved to be good partners in [3+3]cycloadditions, either concerted or not. Several examples involving aryl or alkyl nitrones were described leading to $103,105^{119-121}$ or 104. ${ }^{122}$ Interestingly, these formal dipoles are also effective with less reactive nitrones such as isoquinoline $\mathrm{N}$-oxides leading to $102{ }^{123}$ This reaction with isoquinoline $\mathrm{N}$-oxides proved to be compatible with $N$-alkyl $\alpha$-bromoamides. Depending on the substrate, these reactions are either conducted in fluorinated solvents $^{119,121,122}$ or in acetonitrile, ${ }^{120,122}$ with probably a direct relationship between the solvent used and the mechanism involved. In some cases, the dipole involved in the cycloaddition reaction with the aza-oxyallyl cations is formed in situ like the nitrile imine formed from the hydrazonoyl chloride 108 (Scheme 39). ${ }^{124}$ Alkenylindoles bearing an electron-withdrawing group can also behave as a formal dipole in these basic conditions with $N$-alkoxy $\alpha$ bromoamides to form indole alkaloids with potential antitumor activity. $^{125}$

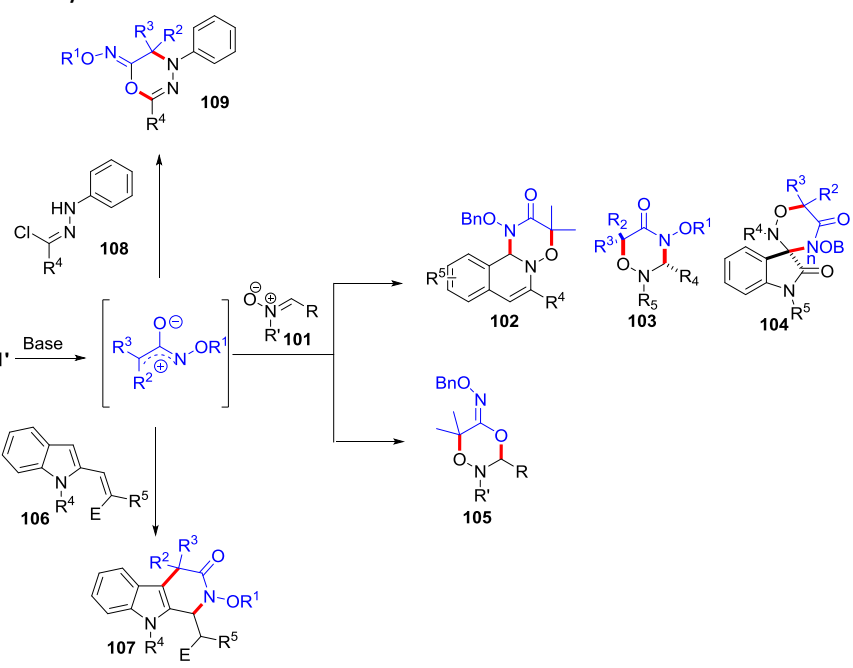


Scheme 39. Examples of [3+3]-cycloadducts obtained from aza-oxyallyl cations

Since the publication of the review by Xuan and co-workers on azaoxyallyl cations, ${ }^{15}$ some new examples have been developed and are listed below.

Recently, Xuan and co-workers reported a [3+3]-cycloaddition reaction with azomethine imines $\mathbf{A}$ generated in situ (Scheme 40). ${ }^{126}$ Under $\mathrm{Ag}(\mathrm{I})$ catalysis, the hydrazide 254 undergoes in acetonitrile a cyclization to form the intermediate azomethine imine A. The isoquinoline-fused triazine derivatives $\mathbf{1 1 1}$ were obtained in good to excellent yields. The same team developed a metal-free version of this cycloaddition reaction in the presence of iodine or bromine $\left(\mathrm{I}_{2}\right.$ or $\left.\mathrm{Br}_{2}\right)$ via the in situ generated $\mathrm{C}, \mathrm{N}$-cyclic azomethine imines. This one-pot process afforded a series of biologically important isoquinoline-fused triazines $\mathbf{1 1 2}$ in good to excellent yields, which contain valuable alkenyl $C-X$ bonds $(X=B r, I)$ (Scheme 40). ${ }^{127}$

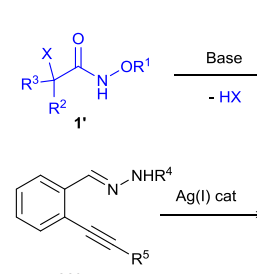

110

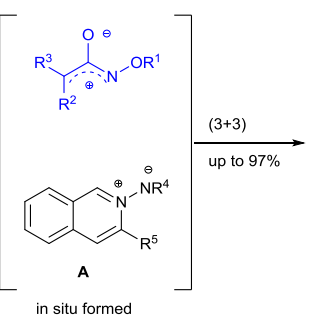<smiles>[R]C1=Cc2ccccc2C2N1N([R])C(=O)C([R])([R])N2[R]</smiles>

111

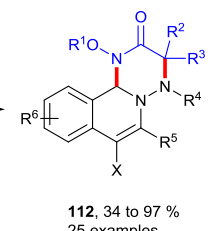

112,34 to $97 \%$
25 examples

Scheme 40. Base-mediated [3+3] cycloaddition of $C, N$-cyclic azomethine imines

1,2,4-Oxadiazin-5-ones 114 were obtained by Xing, Sun and coll. ${ }^{128}$ via a [3+3]-cycloaddition of in situ generated nitrile oxides formed in the basic conditions required for the formation of aza-oxyallyl cations and their reaction with hydroximoyl chlorides 113 . This reaction promoted by $\mathrm{Cs}_{2} \mathrm{CO}_{3}$ as the base in HFIP at room temperature proceeded in good $65-89 \%$ yields (Scheme 21 ).

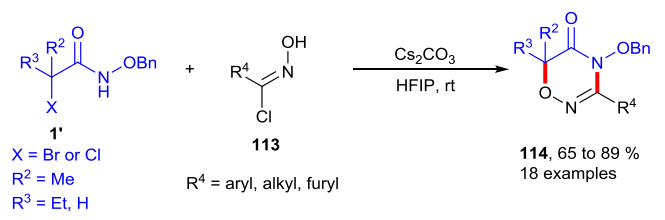

Scheme 21. [3+3] annulation of aza-oxyallyl cations with nitrile oxides

A [3+3]-cycloaddition reaction between azides $\mathbf{1 1 5}$ and once again in situ formed aza-oxyallyl cations in HFIP was performed by Xu et al. (Scheme 42). ${ }^{129}$ In this study, the authors obtained 1,2,3,4tetrazines $\mathbf{1 1 6}$ in good yields under mild conditions.

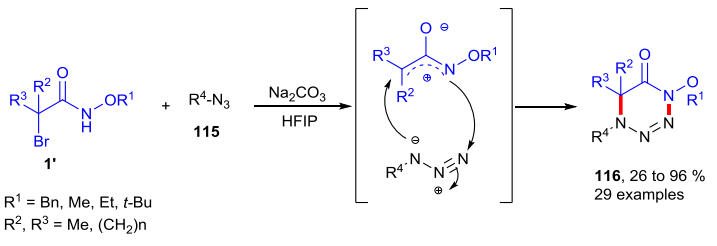

Scheme 42. [3+3] formal cycloaddition of aza-oxyallyl cations with azides

Cycloaddition with nitrones $\mathbf{1 1 7}$ was recently considered as a formal $[3+3]$ annulation reaction (Scheme 43). ${ }^{130,131}$ The best reactions were conducted in $\mathrm{CH}_{3} \mathrm{CN}$ in the presence of $\mathrm{Na}_{2} \mathrm{CO}_{3}$ and the targeted 1,2,4 oxadiazinan-5-ones $\mathbf{1 1 8}$ were obtained with yields up to $99 \%$. The authors proposed the formation of the zwitterion intermediate $\mathbf{A}$ resulting from the nucleophilic attack of the oxygen of the nitrones $\mathbf{1 1 7}$ onto an aza-oxyallyl cation generated in situ from $N$-benzyloxy $\alpha$-bromoamides 1 '. The second step of the domino process was the intramolecular nucleophilic attack of the nitrogen atom of the amide function leading to the final products 118.
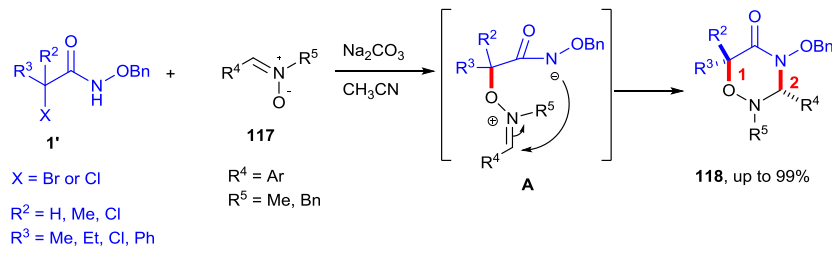

$\mathrm{R}^{3}=\mathrm{Me}, \mathrm{Et}, \mathrm{Cl}, \mathrm{Ph}$

\section{Scheme 43. [3+3] annulation of aza-oxyallyl cations with nitrones}

The fully diastereoselective synthesis of cyclopenta[b]piperazinones 121 was reported by Gandon, Leboeuf and co-workers by a reaction sequence between 2 -furylcarbinols, anilines and $\mathrm{N}$-alkoxy $\alpha$ haloacetamides (Scheme 44). ${ }^{132}$ The scope of the process is wide and allows access to polysubstituted cyclopenta[b] piperazinones 121 in good yields. The proposed mechanism, assessed by DFT computations, does not proceed via an aza-oxyallyl cation. Indeed, the authors were unable to compute the aza-oxyallyl cation previously envisioned. The formation of such zwitterionic species was considered unlikely compared to the corresponding $\alpha$-lactam $\mathbf{A}$. The reaction was proposed to proceed by reaction between the deprotonated form of the aza-Piancatelli product $\mathbf{C}$ and the oxirane2-imine $\mathbf{B}$ resulting from $\mathbf{A}$.

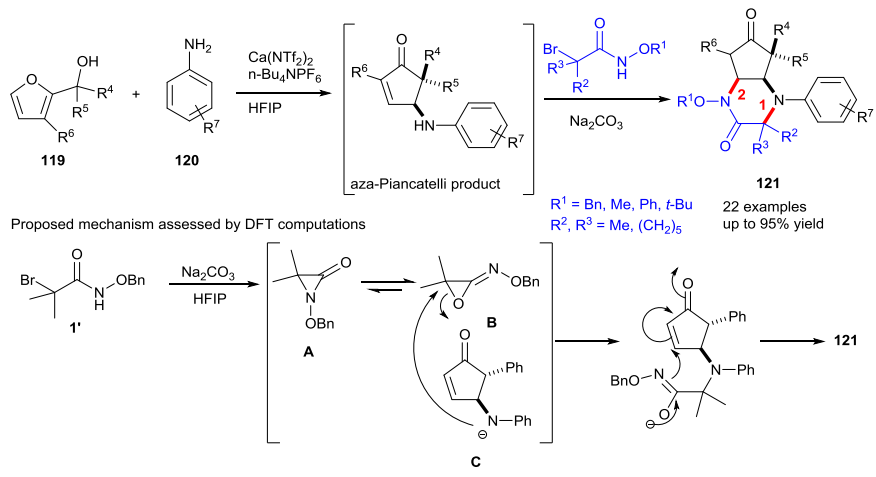




\subsection{Aza-oxyallyl cations in $[3+2]$-cycloadditions and recent developments}

The first examples of [3+2] cycloadditions were given by the teams of Jeffrey, ${ }^{117,133} \mathrm{Wu}^{134}$ and later Liao ${ }^{135}$ on indole derivatives close to 123 . Recently, Zhang et al. ${ }^{136}$ published the total synthesis of $(+/-$ )-minfiensine $\mathbf{1 2 6}$ from the $\mathrm{N}$-protected indole $\mathbf{1 2 5}$ via an efficient [3+2]-cycloaddition between the trichloro acetamide $\mathbf{1}^{\prime}$ and the indole derivative 124 (Scheme 45). In their paper the authors demonstrated that the protection of indole was crucial to obtain $(+/-)$-minfiensine 126. While this type of cycloaddition has been extended to alkynes, ${ }^{137}$ most of the efforts mainly focused on the cycloaddition with dipolarophiles bearing a heteroatom in the double $(C=O, C=N, C=S)$ or the triple $(C \equiv N)$ bond, to form $132^{138-142}$ by reaction with an aldehyde or a ketone, $131^{143-144}$ by reaction with an isothiocyanate or $\mathbf{1 2 9}$ and $\mathbf{1 3 0} 0^{145}$ by reaction with a nitrile. These reactions are mainly performed in fluorinated solvents such as HFIP.

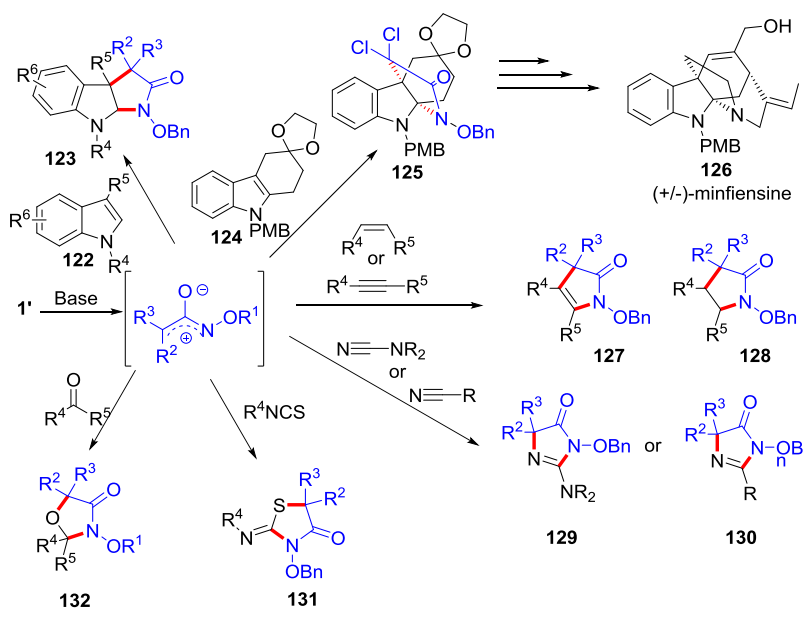

Scheme 45. [3+2] formal cycloaddition of aza-oxyallyl cations

Erden and coworkers ${ }^{146}$ also contributed to this field by developing a [3+2]-cycloaddition from $\mathrm{N}$-benzyloxy-2-chloroamides $\mathbf{1}^{\prime}$ in the presence of $\mathrm{NEt}_{3}$ or $\mathrm{Na}_{2} \mathrm{CO}_{3}$, onto $\mathrm{N}$-arylimines 133 (Scheme 46 ). The desired imidazolidin-4-ones $\mathbf{1 3 5}$ were isolated in moderate to good yields. The same year, Ji and Sun reported an analog [3+2]cycloaddition reaction of arylimines generated in situ from hexahydro-1,3,5-triazines. ${ }^{147}$

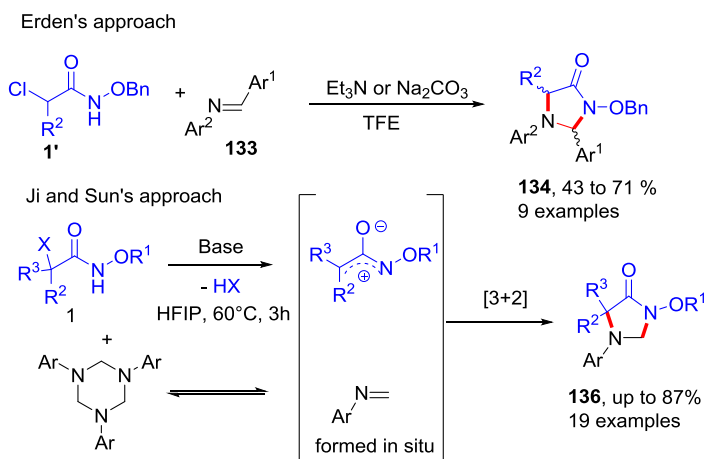

Scheme 46. [3+2]-Cycloadditions with imines

As previously mentioned, alkenes and alkynes were used as cycloaddition partners by several authors. Recently, a [3+2]cycloaddition reaction implicating styrene derivatives 137 was developed by Huang and coworkers. ${ }^{148}$ The multi-substituted pyrrolidinones $\mathbf{1 3 8}$ were consequently obtained in moderate to good yields (Scheme 47). Xu and coworkers also demonstrated the high efficiency of such a process when starting from substituted chalcones 139 and the $\alpha$-bromo $N$-alkoxyamide $\mathbf{1}^{\prime}$ in the presence of $\mathrm{Na}_{2} \mathrm{CO}_{3}$ in HFIP at room temperature (Scheme 47). ${ }^{149}$ Employing this strategy, polysubstituted $\mathrm{p}$-lactams $\mathbf{1 4 0}$ were obtained in good yields.

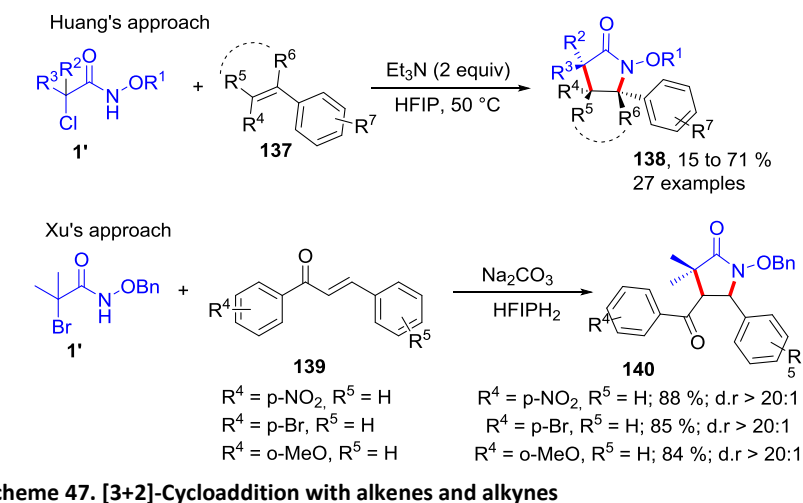

In complement to the previously described reaction with isothiocyanates, ${ }^{143,150,151}$ a reaction between $N$-benzyloxy $\alpha$ bromoamides $1^{\prime}$ and isocyanates $\mathbf{1 4 1}$ has been reported by Wang and coworkers (Scheme 48). ${ }^{152}$ This procedure allows the rapid assembly of hydantoins $\mathbf{1 4 2}$ in good to excellent yields from simple and readily available starting materials. The solvent screening led to the use of $\mathrm{CH}_{3} \mathrm{CN}$ instead of HFIP in which no reaction occurred and to performing the reaction in the presence of $\mathrm{Na}_{2} \mathrm{CO}_{3}$ as a base. In these conditions, the hydantoins $\mathbf{1 4 2}$ were isolated in good to excellent yields. The proposed mechanism involved a domino process via the intermediate A resulting from the nucleophilic addition of the nitrogen atom of isocyanates $\mathbf{1 4 1}$ in $\alpha$ compared to the amide.

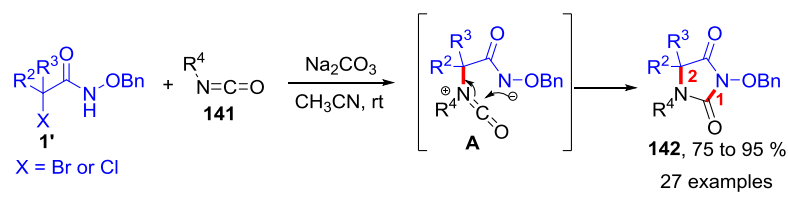

Scheme 48. Domino reaction with isocyanates

These annulation reactions were extended beyond isothiocyanates by Saha, Das and co-workers to thioketones and thioamides with a large diversity of substituents on the thioketones or the thioamides with good to excellent yields. ${ }^{153}$ However, the cycloaddition proved to be poorly diastereoselective (Scheme 49). 


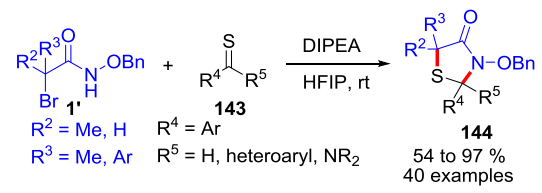

Scheme 49. [3+2] Annulation of thiocarbonyls

A beautiful formal $[3+2]$-cycloaddition reaction was published by Xuan et al. ${ }^{154}$ The starting materials engaged in the process were cyclopropenones $(Y=0)$ or cyclopropenethiones $(Y=S) 145$ together with in-situ-formed azaoxyallyl cations (Scheme 50$)$. Under mild conditions the spirocyclic oxazole $(Y=O)$ or thiazole $(Y=S) 146$ derivatives were isolated in good yields. The authors proposed the formation of the zwitterionic intermediate $\mathbf{A}$ followed by an intramolecular nucleophilic addition of the nitrogen atom.

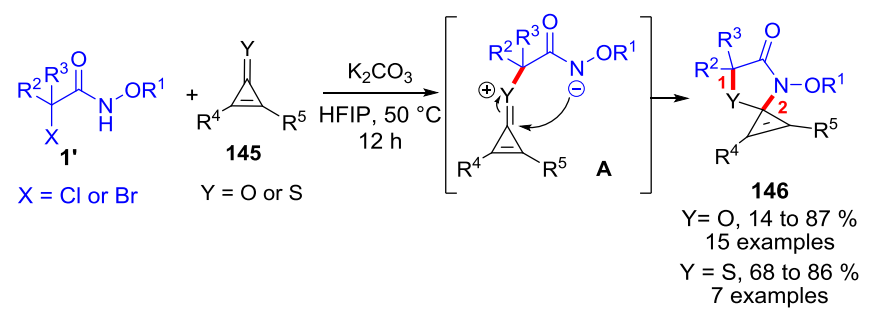

Scheme 50. [3+2] Cycloaddition with cyclopropenones and cyclopropenethiones

An elegant and novel intermolecular approach to access both C3unsubstituted and C3-substituted oxindoles 149 employing an aryne annulation was developed by Prasanthi and co-workers (Scheme 51). ${ }^{155}$ For that purpose, the aryne derivatives were generated in situ from substituted 2-(trimethylsilyl) aryl triflates 147 and were reacted with $\alpha$ haloamides $\mathbf{1}^{\prime}$. It is important to note that the reaction conditions were different from the one classically employed in this chemistry, i.e. the use of THF instead of a fluorinated solvent without a base. Moreover, contrary to the other strategies involving azaoxyallyl cations, primary $\mathrm{N}$-alkoxy $\alpha$ bromoamides $\mathbf{1}^{\prime}\left(R^{2}=R^{3}=H\right)$ were efficient substrates but not disubstituted $N$-alkoxy bromoamides $1^{\prime}\left(R^{2}\right.$ and $\left.R^{3} \neq H\right)$. Thus, the authors considered that the mechanism probably involved a concerted cycloaddition of aryne $\mathbf{1 4 8}$ with transient $\alpha$-lactam B instead of the formation of an azaoxyallyl cation. They also proved that no reaction occurred when a $N$-benzyl amide was engaged, once again demonstrating the dramatic role of the $\mathrm{N}$-alkoxy substituent.

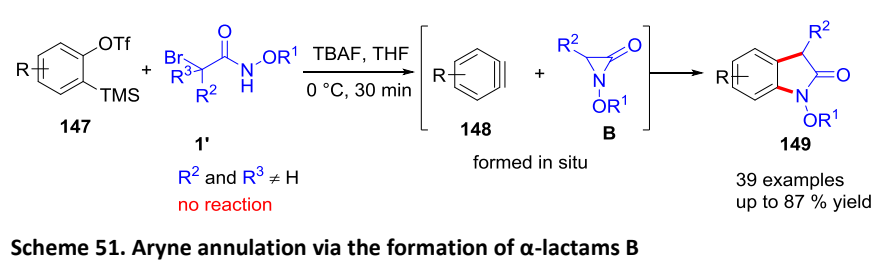

Recently, another [3+2] cycloaddition reaction between azaoxyallyl cations and 1,2-benzisoxazoles $\mathbf{1 5 0}$ or 3-methyl-1,2- benzisoxazoles 152 has been apprehended (Scheme 52). ${ }^{156,}{ }^{157}$ This reaction provides a rapid access to functionalized oxazoline 151 in good yields. It was found that the reaction was sensitive to the substituent onto 1,2-benzoisoxazoles. When 3-methyl-1,2- benzoisoxazoles 152 were used, unstable tricyclic imidazolones 153 were obtained only in $13-16 \%$ yields.

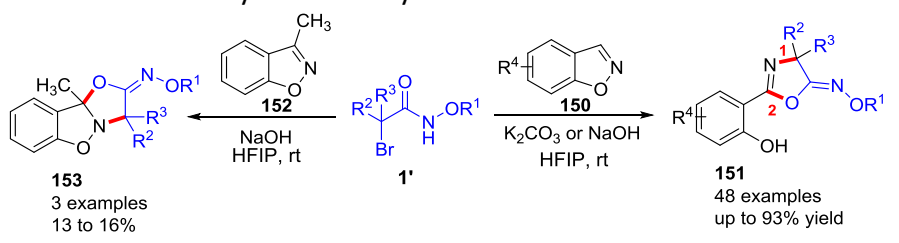

Scheme 52. [3+2] Cycloaddition with 1,2-benzisoxazoles

A beautiful use of $N$-alkoxy $\alpha$-bromoamides $\mathbf{1}^{\prime}$ in a domino reaction was recently published by Chen and co-workers for the regio- and diastereoselective access to 4-imidazolidinones 155 (Scheme 53). ${ }^{158}$ In their paper, the authors clearly demonstrated that $N$-alkoxy $\alpha$ bromoamides 1' reacted with sulfamate-derived cyclic imines 154 via a domino Aza-Mannich/ $\mathrm{S}_{\mathrm{N}} 2$ cyclization, since no reaction occurred in HFIP or when a disubstituted $N$-alkoxy bromoamide $\left(R^{2}\right.$ and $R^{3} \neq \mathrm{H}$ ) was used. Moreover, the reaction proceeded smoothly when primary $N$-alkoxy $\alpha$-bromoamides $(R 2=R 3=H)$ were engaged and $\mathrm{N}$-benzyl amide $\mathbf{1}$ led to the desired product albeit in a lower yield. But more importantly, the reaction between the enantioenriched (R)-1' and unsubstituted sulfamate-derived cyclic imine $\mathbf{1 5 4}$ led to product $\mathbf{1 5 5}$ in $\mathbf{9 5 \%}$ yield with only a minor loss in ee. All these experiments unambiguously prove that the reaction pathway is not via the formation of an azaoxyallyl cation but via a domino aza-Mannich/ $\mathrm{S}_{\mathrm{N}} 2$ cyclization as depicted in the proposed mechanism (Scheme 53).

$$
\text { (s) }
$$

Scheme 53. $N$-alkoxy $\alpha$-bromoamides $X X$ in a domino Aza-Mannich/ $\mathrm{S}_{\mathrm{N}} 2$ cyclization

The cycloadditions with sulfur ylides proved to be very particular, allowing the authors to control the course of the reaction either toward the formation of a 5-membered ring or a 4-membered ring depending on the substituents and the base used (Scheme 54. $[3+2]-$ and $[3+1]$-cycloadditions with sulfur ylides). ${ }^{159}$ In fact, the amidate formed intermediately can either substitute the sulfonium to form the 4-membered ring 159 or add to the carbonyl and eliminate $\mathrm{Me}_{2} \mathrm{~S}$ to form 157 . This versatility of the sulfur ylide leads 
to the formation of two original cycles with modest to high yields selectively.

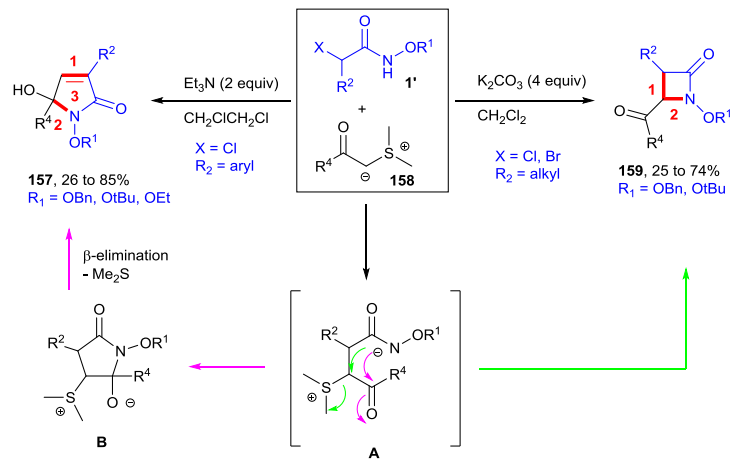

Scheme 54. [3+2]- and [3+1]-cycloadditions with sulfur ylides

A very surprising reactivity of these $N$-alkoxy $\alpha$-bromoamides was reported by Zhang and co-workers. ${ }^{160}$ They observed a basemediated [2+4] annulation with in situ generated aza-o-quinone methides (aza-oQMs) 161 from 160 leading to the formal cycloaddition of the $\mathrm{C}=\mathrm{O}$ bond of the amide. This one-pot [2+4]cycloaddition process led to the 1,4-dihydro-2H-benzo[d][1,3] oxazines 161 in moderate to good yields (Scheme 55).

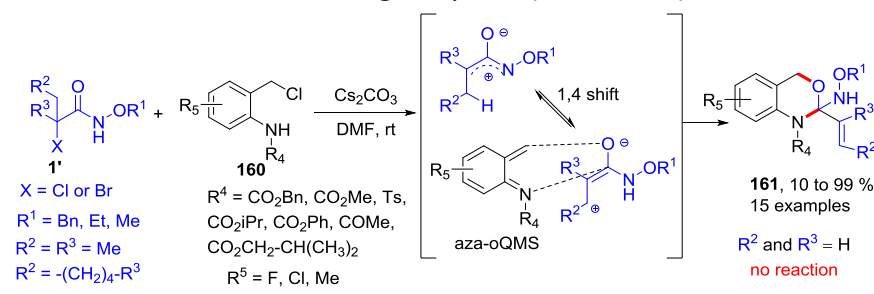

Scheme 55. [2+4] cycloadditions with aza-o-quinone methides aza-oQMs

\section{Conclusion}

Despite the wide scope of reactions involving $\alpha$ halogenoacetamides in domino and/or cycloaddition reactions, the recent developments proceeding by photoredox activation ${ }^{112}$ or involving a Cu promoted coupling step ${ }^{107-108}$ open to several new applications. Anyway, these reactions remain at this time limited to $\alpha$-difluoroacetamides and the extension to other $\alpha$ halogenoacetamides will be one of the challenges to overcome. In addition, the use of $\alpha$-bromoacetamides displaying a chiral center at the carbon atom bearing the bromine in their enantiopure form remain underexploited in these reactions. The reactivity of the species generated in basic conditions is closely related to the substituent onto the nitrogen atom. Hence, aza-oxyallyl cations can be generated in soft conditions from $N$-alkoxy $\alpha$ halogenoacetamides and benefit from the low basicity of the amidate and the high nucleophilicity of the nitrogen from the $\alpha$ effect, allowing several types of cycloadditions. On the contrary, $\mathrm{N}$ alkyl $\alpha$-halogenoacetamides are mostly involved in domino processes usually in the presence of stronger bases. Undoubtedly, there is still an underexploited chemical territory where $N$-alkoxy $\alpha$ - halogenoacetamides can be used as powerful domino partners and $N$-alkyl $\alpha$-halogenoacetamides in cycloaddition reactions. The opportunity to further modulate the reactivity of the nitrogen of the amidate by the presence of electron withdrawing groups lead to several possible new developments starting from $\alpha$ halogenoacetamides.

\section{Conflicts of interest}

There are no conflicts to declare.

\section{Acknowledgements}

We thank the "Fédération de Chimie": FR CNRS 3038 (INC3M), the Région Normandie, the URCOM and IMMM laboratories for their financial support.

\section{Notes and references}

C. M. R. Volla, I. Atodiresei, M. Rueping, Chem. Rev., 2014, 114, 2390.

${ }^{2}$ X.-Y.Chen, S. Li, F. Vetica, M. Kumar, D. Enders, iScience, 2018, 2, 1.

${ }^{3}$ H. Pellissier, Synthesis, 2018, 50, A-H.

${ }^{4}$ C. S. Evans, L. O. Davis, Molecules, 2018, 23, 33.

${ }^{5}$ T. Chanda, J. C.-G. Zhao, Adv. Synth. Catal., 2018, 360, 2.

${ }^{6}$ H. Pellissier, Chem. Rev., 2013, 113, 442.

${ }^{7}$ R. Abonia, J. C. Castillo, Arkivoc., 2018, part ii, 170.

${ }^{8}$ I. Pavlinov, E. M. Gerlach, L. N. Aldrich, Org. Biomol. Chem., 2019, 17,1608

${ }^{9}$ S. L. Kidd, T. J. Osberger, N. Mateu, H. F. Sore, D. R. Spring, Front. Chem., 2018, 6, 460.

${ }^{10}$ S. Yi, B. V. Varun, Y. Choi, S. B. Park, Front. Chem., 2018, 6, 507.

${ }^{11}$ For recent reviews see: (a) J. R. Dunetz, J. Magano, G. A. Weisenburger, Org. Process Res. Dev., 2016, 20, 140 and references therein. (b) C. Chen, F. Verpoort, Q. Wu, RSC Adv., 2016, 6, 55599.

${ }^{12}$ Around 1000 articles disclosing the synthesis and/or use of $\alpha$ halogenoacetamides are published each year since 2005.

${ }^{13}$ (a) R. D. Bach, B. A. Coddens, G. J. Wolber, J. Org. Chem., 1986, 51, 1030. (b) S. S. Shaik, J. Am. Chem. Soc., 1983, 105, 4359. (c) F. Carrion, M. J. S. Dewar, J. Am. Chem. Soc., 1984, 106, 3531. (d) T. I. Yousaf, E. S. Lewis, J. Am. Chem. Soc., 1987, 109, 6137. (e) S. Bhattacharjee, W. Liu, W.-H. Wang, I. Weitzhandler, X. Li, Y. Qi, J. Liu, Y. Pang, D. F. Hunt, A. Chilkoti, ChemBioChem, 2015, 16, 2451. (f) X. He, K. Zhang, Y. Liu, F. Wu, P. Yu, L. Mao, Angewandte Chemie, International Edition, 2018, 57, 4590. (g) Y. Murata, K. Takeuchi, T. Nishikata, Tetrahedron, 2019, 75, 2726. (h) J. M. Fishman, D. B. Zwick, A. G. Kruger, L. L. Kiessling, Biomacromolecules, 2019, 20, 1018.

${ }^{14}$ (a) X.-H. Ouyang, R.-J. Song and J.-H. Li, Chem. - Asian J., 2018, 13, 2316-2332. (b) A. W. Erian, S. M. Sherif and H. M. Gaber, Molecules, 2003, 8, 793-865. (c) I. K. Moiseev, N. V. Makarova and M. N. Zemtsova, Russ. J. Org. Chem., 2003, 39, 1685-1701.

${ }^{15}$ J. Xuan, X. Cao, X. Cheng, Chem. Commun., 2018, 54, 5154.

${ }^{16}$ A. Andreani, S. Burnelli, M. Granaiola, A. Leoni, A. Locatelli, R. Morigi, M. Rambaldi, L. Varoli, L. Landi, C. Prata, M. V. Berridge, C. 
Grasso, H.-H. Fiebig, G. Kelter, A. M. Burger, M. W. Kunkel, J. Med. Chem., 2008, 51,4563.

${ }^{17}$ K. Kanoh, S. Kohno, T. Asari, T. Harada, J. Katada, M. Muramatsu, H. Kawashima, H. Sekiya, I. Uno, Bioorg.Med. Chem. Lett., 1997, 7, 2847.

${ }^{18}$ N. Rameshkumar, M. Ashokkumar, E. H. Subramanian, R. Ilavarasan, S. K. Sridhar, Eur. J. Med. Chem., 2003, 38, 1001.

${ }^{19}$ K. McCleland, P. J. Milne, F. R. Lucieto, C. Frost, S. C. Brauns, M. van De Venter, J. Du Plessis, K. Dyason, J. Pharm. Pharmacol., 2004, 56, 1143.

${ }^{20}$ K. J. Emery, T. Tuttle, J. A. Murphy, Org. Biomol. Chem., 2017, 15, 8810.

${ }^{21}$ W. Liu, H. Cao, H. Zhang, H. Zhang, K. H. He, C. Chung, H. Wang, F. Y. Kwong, A. Lei, J. Am. Chem. Soc., 2010, 132, 16737.

${ }^{22}$ W.-C. Chen, Y.-C. Hsu, W.-C. Shih, C.-Y. Lee, W.-H. Chuang, Y.-F. Tsai, P. P.-Y. T.-G. Chen, Ong, Chem. Commun., 2012, 48, 6702.

${ }^{23}$ Y. Qiu, Y. Liu, K. Yang, W. Hong, Z. Li, Z. Wang, Z. Yao, S. Jiang, Org. Lett., 2011, 13, 3556.

${ }^{24}$ E. Shirakawa, K.-i. Itoh, T. Higashino, T. Hayashi, J. Am. Chem. Soc., 2010, 132, 15537.

${ }^{25}$ H. Bonin, M. Sauthier, F.-X. Felpin, Adv. Synth. Catal., 2014, 356, 645.

${ }^{26}$ S. Yanagisawa, K. Ueda, T. Taniguchi, K. Itami, Org. Lett., 2008, 10, 4673.

${ }^{27}$ C.-L. Sun, Z.-J. Shi, Chem. Rev., 2014, 114, 9219.

${ }^{28}$ T. Okawara, Y. Noguchi, T. Matsuda, M. Furukawa, Chem. Lett., 1981, 10, 185.

${ }^{29}$ O’Reilly, E.; Lestini, E.; Balducci, D.; Paradisi, F. Tetrahedron Letters, 2009, 50, 1748.

${ }^{30}$ Cho, S.-D.; Song, S.-Y.; Kim, K.-H.; Zhao, B.-X.; Ahn, C.; Joo, W.-H.; Yoon, Y.-J.; Falck, J. R.; Shin, D.-S. Bull. Korean Chem. Soc. 2004, 25, 415.

${ }^{31}$ Hazra, A. Paira, P. Palit, P. Banerjee, S. Mondal, N. B. Sahu, N. P. J. Chem. Res. 2007, 7, 381.

${ }^{32}$ D’Angeli, F.; Marchetti, P.; Rondanin, R.; Bertolasi, V.; J. Org. Chem. 1996, 61, 1252.

${ }^{33}$ T. Mancilla, L. Carillo, L. S. Zamudio-Riviera, H. I. Beltrán, N. Farfán, Org. Prep. Proc. Int., 2002, 34, 87.

${ }^{34}$ M. M. Ghorab, M. S. A. El Gaby, N. E. Amin, N. M. H. Taha, M. A. Shehab, I. M. I. Faker, Phosphorus, Sulfur, and Silicon, 2008, 183, 2929.

${ }^{35}$ (a) M. A. Casadei, B. Di Rienzo, A. Inesi, F. M. Moracci, J. Chem Soc. Perkin Trans. 1, 1992, 379. (b) M. A. Casadei, B. Di Rienzo, A. Inesi, F. M. Moracci, J. Chem Soc. Perkin Trans 1, 1992, 375.

${ }^{36}$ I. Allous, S. Comesse, A. Daïch, Lett. Org. Chem., 2008, 5, 73.

${ }^{37}$ I. Allous, S. Comesse, D. Berkeš, A. Alkyat, A. Daïch, Tetrahedron Lett., 2009, 50, 4411.

${ }^{38}$ M. M. Rammah, M. Othman, M. B. Rammah, J. Soc Chim. Tunis. 2008, 10, 131.

${ }^{39}$ M. Toshima, S. Watanabe, K. Uchiyama, T. Takasaki, N. N. Bhogle, H. Zhao, M. Filios, K. Takahashi, J. R. Snoonian, K. Saranteas, Org. Process Res. Dev., 2016, 20, 1239.

${ }^{40}$ M.T.M. Sarg, S.S. El-Shaer, Open Journal of Medicinal Chemistry, 2014, 4, 39

${ }^{41}$ A.-E.-B. A. G. Ghattas, A. Khodairy, H. M. Moustafa, B. R. M. Hussein, M. M. Farghaly, M. O. Aboelez, Pharmaceutical Chemistry Journal, 2017, 51, 652.

${ }^{42}$ N. Oukli, S. Comesse, N. Chafi, H. Oulyadi, A. Daïch, Tetrahedron Lett., 2009, 50, 1459 and references therein.
${ }^{43}$ A. V. Tverdokhlebov, E. V. Resnyanska, A. V. Zavada, A. A. Tolmachev, A. N. Kostyukd, A. N. Chernega, Tetrahedron, 2004, 60, 5777.

${ }^{44}$ A. Pesquet, M. Othman, Tetrahedron Lett., 2013, 54, 5227.

${ }^{45}$ S. Gao, Y. Q. Tu, X. Hu, S. Wang, R. Hua, Y. Jiang, Y. Zhao, X. Fan, S. Zhang, Org. Lett., 2006, 8, 2373.

${ }^{46}$ M. D. Rose, M. P. Cassidy, P. Rashatasakhon, A. Padwa, J. Org. Chem., 2007, 72, 538.

${ }^{47}$ T. Morikawa, S. Harada, A. Nishida, J. Org. Chem., 2015, 80, 8859.

${ }^{48}$ B. M. Kwon, J. W. Park, J. Heterocycl. Chem., 1983, 20, 1725.

${ }^{49}$ M. H. Bolli, S. Abele, C. Binkert, R. Bravo, S. Buchmann, D. Bur, J. Gatfield, P. Hess, C. Kohl, C. Mangold, B. Mathys, K. Menyhart, C. Muller, O. Nayler, M. Scherz, G. Schmidt, V. Sippel, B. Steiner, D. Strasser, A. Treiber, T. Weller, J. Med. Chem., 2010, 53, 4198.

${ }^{50}$ S. Saxena, G. Samala, J. P.P. Sridevi, B. Devi, P. Yogeeswari, D. Sriram, Eur. J. Med. Chem., 2015, 92, 401.

${ }^{51}$ A. Mobinikhaledi, N. Foroughifar, S. Faghihi, Phosphorus, Sulfur, and Silicon and the Related Elements, 2009, 184, 1837.

${ }^{52}$ G. Saravanan, R. Selvaraju, S. Nagarajan, Synthetic Communication, 2012, 42, 3361.

${ }^{53}$ L. Ma, H. Pei, L. Lei, L. He, J. Chen, X. Liang, A. Peng, H. Ye, M. Xiang, L. Chen, Eur. J. Med. Chem., 2015, 92, 178.

${ }^{54}$ W. Zheng, A. Degterev, E. Hsu, J. Yuan, C. Yuan, Bioorg. Med. Chem. Lett., 2008, 18, 4932.

${ }^{55}$ A. Elkamhawy, N. Y. Kim , A. H. E. Hassan, J.-E. Park, J.-E. Yang, K.S. Oh, B. H. Lee, M. Y. Lee, K. J. Shin, K.-T. Lee, W. Hur, E. J. Roh, Eur. J. Med. Chem., 2018, 157, 691.

${ }^{56}$ G. Wang, X. Wang, H. Yu, S. Wei, N. Williams, D. LHolmes, R. Halfmann, J. Naidoo, L. Li, L. Wang, S. Chen, P. Harran, X. Lei, X. Wang, Nature Chemical Biology, 2012, 9, 84.

${ }^{57}$ A. J. Suresh, K. Bharathi, P. R. Surya, J. Pharm. Chem. Bio.I Sci., 2017, 5, 312.

${ }^{58}$ F. Alam, B. K. Dey, A. Chakraborty, Int. Res. J. Pharm., 2014, 5, 325.

${ }^{59}$ H.-L. Liu, Z. Li, T. Anthonsen, Molecules, 2000, 5, 1055.

${ }^{60}$ R. Lakhan, Singh, R. L. J. Agrie. Food Chem., 1991, 39, 580.

${ }^{61}$ H.M. Kasralikar, S.C. Jadhavar, S.V. Goswami, N.S. Kaminwar, S.R. Bhusare, Bioorganic Chemistry, 2019, 86, 437.

${ }^{62}$ P. Marchetti, Tetrahedron Lett., 2003, 44, 4121.

${ }^{63}$ P. Scrimin, F. D’Angeli, A. C. Veronese, V. Baioni, Tetrahedron Lett., 1983, 24, 4473.

${ }^{645}$ F. D'angeli, G. Cavicchioni, G. Catelani, P. Marchetti, F. Maran, Gazz. Chim. Ital., 1989, 119, 471.

${ }^{65}$ G. Cavicchioni, F. D'Angeli, A. Casolari, P. Orlandini, Synthesis, 1988, 1988, 947.

${ }^{66}$ F. Maran, E. Vianello, J. Chem. Soc. Perkin Trans. II, 1987, 33.

${ }^{67}$ A. C. Veronese, P. Scrimin, G. Vecchiati, S. Sferra, F. D'Angeli, J. Chem. Soc. Perkin. Trans. I, 1984, 781.

${ }^{68}$ A. El Bouakher, R. Le Goff, J. Tasserie, J. Lhoste, A. Martel, S. Comesse, Org. Lett., 2016, 18, 2383.

${ }^{69}$ M. A. Casadei, S. Cesa, A. Inesi, Tetrahedron, 1995, 51, 5891.

${ }^{70}$ M. A. Casadei, S. Cesa, F. M. Moracci, J. Org. Chem., 1996, 61, 380.

${ }^{71}$ S. Cesa, V. Mucciante, L. Rossi, Tetrahedron, 1999, 55, 193.

${ }^{72}$ G. Galliani, B. Rindone, F. Saliu, Tetrahedron Lett., 2009, 50, 5123.

${ }^{73}$ H. Rmedi, A. Baklouti, Tetrahedron Lett., 2014, 55, 3585.

${ }^{74}$ B. Kishore, G. Brahmeshwari, Heterocyclic Letters, 2018, 8, 631. 
${ }^{75}$ E. Rajanarendra, A. S. R. Reddy, K. G. Reddy, S. Raju, Indian Journal of Chemistry, 2011, 50B, 1800.

${ }^{76}$ E. Ščerbetkaitè, R. Tamulienè, A. Bieliauskas, A. Šačkus, Molbank, 2017, 2017, 1

${ }^{77}$ A. Sackus, S. Krikstolaityte, V. Martynaitis, Chemistry of Heterocyclic Compounds, 1999, 35, 575.

${ }^{78}$ E. Valaityte, V. Martynaitis, A. Sackus, Chemistry of Heterocyclic Compounds, 2004, 40, 1460.

${ }^{79}$ K. W. Hering, K. Karaveg, K. W. Moremen, W. H. Pearson, J. Org. Chem., 2005, 70, 9892.

${ }^{80}$ G. Revelant, S. Huber-Villaume, S. Dunand, G. Kirsch, H. Schohn, S. Hesse, Eur. J. Med. Chem., 2015, 94, 102.

${ }^{81}$ S. Vodela, R. V. Reddy Mekala, H. Gadegoni, International Journal of Biomedical Research, 2014, 05, 5-10.

${ }^{82}$ G. Revelant, S. Hesse, G. Kirsch, Synthesis, 2010, 19, 3319.

${ }^{83}$ M. H. Bolli, S. Abele, C. Binkert, R. Bravo, S. Buchmann, D. Bur, J. Gatfield, P. Hess, C. Kohl, C. Mangold, B. Mathys, K. Menyhart, C. Müller, O. Nayler, M. Scherz, G. Schmidt, V. Sippel, B. Steiner, D. Strasser, A. Treiber, T. Weller, J. Med. Chem., 2010, 53, 4198.

${ }^{84}$ P. F. Lamie, J. N. Philoppes, Med Chem Res., 2017, 26, 1228.

${ }^{85}$ E. Rajanarendar, S. Raju, A. Siva Rami Reddy, Phosphorus, Sulfur, and Silicon, 2009, 184, 3139.

${ }^{86}$ F. M. Moghaddam, L. Hojabri, J. Heterocycl. Chem., 2007, 44, 35.

${ }^{87}$ E. Rajanarendar, E. Kalyan Rao, F. P. Shaik, M. N. Reddy, M. Srinivas, J. Sulfur Chem., 2010, 31, 263.

${ }^{88} \mathrm{H}$. Walter, Heterocycles, 1995, 41, 2427.

${ }^{89}$ G. Cavicchioni, P. Scrimin, A. C. Veronese, F. D'Angeli, J. Chem. Soc. Chem. Comm., 1981, 416.

${ }^{90}$ S. Comesse, M. Sanselme, A. Daïch, J. Org. Chem., 2008, 73, 5566.

${ }^{91}$ I. Allous, S. Comesse, M. Sanselme, A. Daïch, Eur. J. Org. Chem., 2011, 5303.

${ }^{92}$ M. Saber, S. Comesse, V. Dalla, A. Daïch, M. Sanselme, P. Netchitaïlo, Synlett., 2010, 2010, 2197.

${ }^{93}$ M. Saber, S. Comesse, V. Dalla, P. Netchitaïlo, A. Daïch, Synlett., 2011, 2011, 2425.

${ }_{94}$ R. Le Goff, M. Sanselme, A. M. Lawson, A. Daïch, S. Comesse, Eur. J. Org. Chem., 2015, 7244.

${ }^{95}$ R. Le Goff, A. Martel, M. Sanselme, A. M. Lawson, A. Daïch, S. Comesse, Chem. Eur. J., 2015, 21, 2966.

${ }^{96}$ S. Comesse, A. Martel, A. Daïch, Org. Lett., 2011, 13, 4004.

${ }^{97}$ A.; El Bouakher, J. Tasserie, R. Le Goff, J. Lhoste, A. Martel, S. Comesse, J. Org. Chem., 2017, 82, 5798.

${ }^{98}$ S. Mizutani, K. Komori, T. Taniguchi, K. Monde, K. Kuramochi, K. Tsubaki, Angew. Chem. Int. Ed., 2016, 55, 9553.

${ }^{99}$ K. Komori, T. Taniguchi, S. Mizutani, K. Monde, K. Kuramochi, K. Tsubaki, Org. Lett., 2014, 16, 1386.

${ }^{100}$ S. Mizutani, K. Komori, C. Kai, K. Kuramochi, K. Tsubaki, Tetrahedron, 2016, 72, 6640.

${ }^{101}$ J. Guo, X. Sun, S. Yu, Org. Biomol. Chem., 2014, 12, 265-268.

102 D. Chen, G. Shen, W. Bao, Org. Biomol. Chem., 2009, 7, 4067.

${ }^{103}$ F. Yin, G. Feng, Q. Song, C. Qi, J. Chem. Res., 2012, 41.

${ }^{104}$ P. Diz, P. Pernas, A. El Maatougui, C. R. Tubio, J. Azuaje, E. Sotelo, F. Guitian, A. Gil, A. Coelho, Applied Catalysis A: General, 2015, 502, 86.

${ }^{105}$ Y. Yamane, K Miyazaki, T. Nishikata, ACS Catal. 2016, 6, 7418.

${ }^{106}$ H. Chen, X. Wang, M. Guo, W. Zhao, X. Tang, G. Wang, Org. Chem. Front., 2017, 4, 2403.

${ }^{107}$ Y. Lv, W. Pu, Q. Wang, Q. Chen, J. Niu, Q. Zhang, Adv. Synth. Catal., 2017, 359, 3114.
${ }^{108}$ Y. Lv, W. Pu, Q. Chen, Q. Wang, J. Niu, Q. Zhang, J. Org. Chem., 2017, 82, 8282.

${ }^{109}$ S. Iyer, C. Ramesh, G. M. Kulkarni, Synlett., 2001, 8, 1241.

${ }^{110}$ N. Kanbayashi, K. Takenaka, T. Okamura, K. Onitsuka, Angew.

Chem. Int. Ed., 2013, 52, 4897.

${ }^{111}$ B.-H. Li, K.-L. Li, Q.-Y. Chen, J. Fluorine Chem., 2012, 133, 163.

${ }_{112}$ M. Zhang, W. Li, Y. Duan, P. Xu, S. Zhang, C. Zhu, Org. Lett., 2016, 18, 3266.

${ }^{113}$ L. Ye, K.-Y. Lo, Q. Gu, D. Yang, Org. Lett., 2017, 19, 308.

${ }^{114}$ C. S. Jeffrey, K. L. Barnes, J. A. Eickhoff and C. R. Carson, Journal of the American Chemical Society, 2011, 133, 7688.

${ }^{115}$ K. L. Barnes, A. K. Koster and C. S. Jeffrey, Tetrahedron Letters, 2014, 55, 4690.

${ }^{116}$ C. Jeffrey, A. Acharya and J. Eickhoff, Synthesis, 2013, 45, 1825.

${ }^{117}$ A. Acharya, J. A. Eickhoff, K. Chen, V. J. Catalano and C. S. Jeffrey, Organic Chemistry Frontiers, 2016, 3, 330.

118 J. Feng, M. Zhou, X. Lin, A. Lu, X. Zhang, M. Zhao, Organic Letters, 2019, 21, 6245.

${ }^{119}$ H.-W. Zhao, Y.-D. Zhao, Y.-Y. Liu, L.-J. Zhao, N.-N. Feng, H.-L. Pang, X.-Q. Chen, X.-Q. Song and J. Du, RSC advances, 2017, 7, 12916.

120 J. Xuan, X. Cheng and X. Cao, ChemistrySelect, 2017, 2, 4364.

${ }^{121}$ Q. Jia, D. Li, M. Lang, K. Zhang and J. Wang, Advanced Synthesis \& Catalysis, 2017, 359, 3837.

${ }^{122}$ W. Lin, G. Zhan, M. Shi, W. Du and Y. Chen, Chin. J. Chem . 2017, 35, 857.

${ }^{123}$ Y. An, H. Xia and J. Wu, Chemical communications, 2016, 52, 10415-10418.

${ }^{124}$ H.-W. Zhao, Y.-D. Zhao, Y.-Y. Liu, L.-J. Zhao, X.-Q. Song, X.-Q. Chen, H.-L. Pang, J. Du and N.-N. Feng, RSC advances, 2017, 7, 55106.

${ }^{125}$ K. Zhang, X. Xu, J. Zheng, H. Yao, Y. Huang and A. Lin, Org. Lett., 2017, 19, 2596.

${ }^{126}$ X. Cheng, X. Cao, J. Xuan and W.-J. Xiao, Org. Lett., 2018, 20, 52.

${ }^{127}$ X. Cheng, X. Cao, S. J. Zhou, B. G. Cai, X. K. He and J. Xuan, Advanced Synthesis \& Catalysis, 2019, 361, 1230.

${ }^{128}$ G. Wang, R. Chen, S. Zhao, L. Yang, H. Guo, S. Sun, J. Wang, J. Domena and Y. Xing, Tetrahedron Letters, 2018, 59, 2018.

${ }^{129}$ X. Xu, K. Zhang, P. Li, H. Yao and A. Lin, Organic letters, 2018, 20, 1781.

${ }^{130}$ R. Chen, S. Sun, G. Wang and H. Guo, Tetrahedron Letters, 2018, 59, 1916.

${ }^{131}$ R. Chen, S. Zhao, Y. Fu, Y. Zhang, H. Guo, G. Wang, S. Sun and Y. Xing, Heterocycl. Commun., 2018, 24, 71.

${ }_{132}$ B. Balde, G. Force, L. Marin, R. Guillot, E. Schulz, V. Gandon and D. Leboeuf, Organic letters, 2018, 20, 7405.

${ }^{133}$ D. Anumandla, A. Acharya and C. S. Jeffrey, Organic letters, 2016, $18,476$.

${ }^{134}$ M. C. DiPoto, R. P. Hughes and J. Wu, Journal of the American Chemical Society, 2015, 137, 14861.

${ }^{135}$ W. Ji, L. Yao and X. Liao, Organic letters, 2016, 18, 628.

${ }^{136}$ C. Zhang, W. Ji, Y. A. Liu, C. Song and X. Liao, Journal of natural products, 2018, 81, 1065.

${ }^{137}$ G. Wang, R. Chen, M. Wu, S. Sun, X. Luo, Z. Chen, H. Guo, C. Chong and Y. Xing, Tetrahedron Letters, 2017, 58, 847.

${ }^{138}$ K. Zhang, C. Yang, H. Yao and A. Lin, Organic letters, 2016, 18, 4618.

${ }^{139}$ A. Acharya, K. Montes and C. S. Jeffrey, Organic letters, 2016, 18, 6082.

${ }^{140}$ Q. Jia, Z. Du, K. Zhang and J. Wang, Organic Chemistry Frontiers, 2017, 4, 91. 
${ }^{141}$ S. Jiang, K. Li, J. Yan, K. Shi, C. Zhao, L. Yang and G. Zhong, The Journal of organic chemistry, 2017, 82, 9779.

142 P. L. Shao, Z. R. Li, Z. P. Wang, M. H. Zhou, Q. Wu, P. Hu and Y. He, The Journal of organic chemistry, 2017, 82, 10680.

${ }^{143}$ G. Wang, S. Zhao, R. Chen, L. Yang, J. Wang, H. Guo, M. Wu, J. Domena, Y. Xing and S. Sun, Tetrahedron Letters, 2017, 58, 4308.

${ }^{144}$ H.-W. Zhao, Y.-D. Zhao, Y.-Y. Liu, J. Du, H.-L. Pang, X.-Q. Chen, X.Q. Song and N.-N. Feng, European Journal of Organic Chemistry, 2017, 2017, 3466.

${ }^{145}$ M. C. DiPoto and J. Wu, Org. Lett., 2018, 20, 499.

146 O. Eyilcim, S. Issever, N. Ocal, S. Gronert and I. Erden, Tetrahedron Letters, 2018, 59, 3674.

${ }^{147}$ D. Ji and J. Sun, Organic letters, 2018, 20, 2745.

${ }^{148}$ Y. Zhang, H. Ma, X. Liu, X. Cui, S. Wang, Z. Zhan, J. Pu and G. Huang, Organic \& biomolecular chemistry, 2018, 16, 443.

${ }^{149}$ P. S. Gao, K. Zhang, M. M. Yang, S. Xu, H. M. Sun, J. L. Zhang, Z. W. Gao, W. Q. Zhang and L. W. Xu, Chemical Communications, 2018, 54, 5074.

${ }_{150}$ F. M. Moghaddam and L. Hojabri, Journal of Heterocyclic Chemistry, 2007, 44, 35.

${ }^{151}$ H. Yoshino, H. Sato, T. Shiraishi, K. Tachibana, T. Emura, A. Honma, N. Ishikura, T. Tsunenari, M. Watanabe, A. Nishimoto, R. Nakamura, T. Nakagawa, M. Ohta, N. Takata, K. Furumoto, K. Kimura and H. Kawata, Bioorganic \& medicinal chemistry, 2010, 18, 8150.

${ }^{152}$ S. Sun, R. Chen, G. Wang and J. Wang, Organic \& biomolecular chemistry, 2018, 16, 8011 .

${ }^{153}$ V. Jaiswal, B. Mondal, K. Singh, D. Das and J. Saha, Organic Letters, 2019, 21, 5848.

${ }^{154}$ S.-J. Zhou, X. Cheng, J. Xuan, Asian Journal of Organic Chemistry, 2019, 8, 1376.

${ }^{155}$ R. Singh, K. Nagesh, D. Yugandhar and A. V. G. Prasanthi, Organic letters, 2018, 20, 4848.

${ }^{156}$ J. Feng, M. Zhao, X. Lin, The Journal of Organic Chemistry, 2019, 84, 9548.

157 L. Sun, Y. Liu, Y. Wang, Y. Li, Z. Liu, T. Lu, W. Li, Organic \& Biomolecular Chemistry, 2019, 17, 7526.

158 J. Zhou, H. Zhang, X.-L. Chen, Y.-L. Qu, Q. Zhu, C.-G. Feng and Y.-J. Chen, The Journal of Organic Chemistry, 2019, 84, 9179.

${ }^{159}$ C. Li, K. Jiang, Q. Ouyang, T. Y. Liu and Y. C. Chen, Organic letters, 2016, 18, 2738.

${ }^{160}$ Q. Jin, M. Gao, D. Zhang, C. Jiang, N. Yao and J. Zhang, Organic \& Biomolecular Chemistry, 2018, 16, 7336. 